\title{
Cholinergic Modulation of Appetite-Related Synapses in Mouse Lateral Hypothalamic Slice
}

\author{
Young-Hwan Jo, Denise Wiedl, and Lorna W. Role \\ Department of Anatomy and Cell Biology in the Center for Neurobiology and Behavior, Columbia University, College of Physicians and Surgeons, New \\ York, New York 10032
}

\begin{abstract}
Nicotine administration reduces appetite and alters feeding patterns; a major deterrent to smoking cessation is hyperphagia and resultant weight gain. We demonstrate here that lateral hypothalamic ( $\mathrm{LH})$ circuits involving melanin-concentrating hormone (MCH) neurons are subject to cholinergic modulation that may be related to the effects of nicotine on appetite control. Cholinergic input to the perifornical LH area of the mouse is confirmed by examination of immunostaining for vesicular acetylcholine (ACh) transporter (VAT) in conjunction with antibodies to $\mathrm{MCH}$ and the vesicular GABA transporter (vGABAT). vAChT-positive neurons border the LH, and VAT-positive projections are detected throughout the perifornical area. $\mathrm{MCH}$-positive dendrites appear studded with vGABAT-positive contacts, consistent with recordings of GABAergic inputs to LH/MCH neurons identified by their location, morphology, electrophysiological profile, and MCH expression. Activation of presynaptic nicotinic ACh receptors (nAChRs) enhances GABAergic transmission. GABAergic transmission is potentiated by (1) direct nicotine application, (2) increasing local ACh concentration, and (3) stimulation of cholinergic projections. Based on pharmacological studies and comparisons of wild-type versus $\alpha 7 \mathrm{nAChR}$ subunit mutant mice, we propose that $\alpha 7^{\star}$-nAChRs are required for the modulation of GABAergic inputs in LH. Prenatal exposure to nicotine elicits a persistent elevation of GABAergic transmission in the LH of postnatal pups. Furthermore, GABAergic inputs to LH of prenatal nicotine-exposed pups are insensitive to subsequent nicotine challenge. Our studies support the hypothesis that nicotine administration or elevated cholinergic tone enhance inhibition of perifonical LH/MCH neurons via activation of presynaptic $\alpha 7^{\star}$-nAChRs.
\end{abstract}

Key words: MCH; orexin; nicotine; motivation; reward; obesity

\section{Introduction}

Nicotine, the major addictive component in tobacco, reduces appetite and alters feeding patterns typically resulting in reduced body weight (Grunberg, 1986; Grunberg et al., 1986; Miyata et al., 1999; Jo et al., 2002). Particularly striking is the hyperphagia and resultant weight gain that typically accompanies smoking cessation (Grunberg et al., 1986; Klesges et al., 1989; Pomerleau et al., 2000). Direct application of nicotine in the region of the LH (this paper) or in synaptic preparations of LH neurons in vitro enhances GABAergic transmission (Jo and Role, 2002). The effects of ACh per se appear to be more complex, because activation of muscarinic ACh receptors (AChRs) oppositely modulated GABAergic transmission. Previous in vitro studies underscored an important potential role of endogenous cholinoceptive systems in the lateral hypothalamus (LH) and further implicated $\mathrm{ACh}$ in the regulation of feeding-related circuits and synapses.

Received March 19, 2004; revised 0ct. 5, 2005; accepted 0ct. 19, 2005.

This work was supported by National Institutes of Health Grant NS22061 (L.W.R.) and by an award from the New York Obesity Research Center to (Y.-H.J.). We thank Dr. M. Nason for input on the prenatal nicotine exposure studies and for comments on this manuscript.

Correspondence should be addressed to Dr. Lorna W. Role, Columbia University, College of Physicians and Surgeons, Center for Neurobiology, 1051 Riverside Drive, P. I. Annex, Room 807, New York, NY 10032. E-mail: Iwr1@columbia.edu.

Y.-H.J.'s present address: Albert Einstein College of Medicine, Department of Medicine, Division Of Endocrinology, 1300 Morris Park Avenue, Bronx, NY 10461.

DOI:10.1523/JNEUROSCI.3638-05.2005

Copyright $\odot 2005$ Society for Neuroscience $\quad$ 0270-6474/05/2511133-12\$15.00/0
The LH is the recipient of several sources of cholinergic projections with inputs from the brainstem (pedunculopontine and laterodorsal tegmental areas) as well as from local cholinergic cell groups (substantia innominata and zona incerta) (Grove, 1988; Woolf, 1991; Bayer et al., 1999). There are numerous reports demonstrating that chronic nicotine exposure can regulate the expression and/or function of nicotinic AChRs (nAChRs) (Yates et al., 1995; Olale et al., 1997; Peng et al., 1997; Ke et al., 1998; Molinari et al., 1998; Wang et al., 1998; Fenster et al., 1999; Buisson and Bertrand, 2001; Gentry and Lukas, 2002; Slotkin et al., 2002; Pakkanen et al., 2005). In contrast, there is relatively little information about effects of prenatal nicotine exposure on postnatal alterations in synaptic transmission or on persistent changes in the profile of nAChR-mediated modulation of CNS transmission in general and in hypothalamic circuits in particular. The current study establishes a potential role of nAChR activation in the short- and long-tern regulation of excitability in feeding-related synapses.

Mice lacking melanin-concentrating hormone $(\mathrm{MCH})$ have lowered body weight, are lean, and display marked hypophagia compared with control animals (Shimada et al., 1998). Recent studies showing that $\mathrm{MCH}$ receptor-deficient mice, like those lacking $\mathrm{MCH}$ expression, are lean, further supporting the importance of MCH in appetite regulation (Marsh et al., 2002). Projections of the $\mathrm{MCH}$ neurons include the nucleus accumbens and the ventral tegmental area, prominent reward-related areas. As 
such, these relays may play a unique role in enhancing the hedonic value of food intake.

We focused the current analysis on testing whether the activation of $\mathrm{nAChRs}$ might modulate GABAergic inputs involved in the regulation of feeding circuits within the LH. We also initiated studies testing the hypothesis that prenatal exposure to nicotine might exert long-lasting effects on the GABAergic transmission at LH synapses and alter the responsiveness of these circuits to subsequent cholinergic modulation.

\section{Materials and Methods}

Slice preparation. Transverse brain slices were prepared from wild-type C57BL/6 or $\alpha 7$ knock-out (KO) mice (Orr-Urtreger et al., 1997) at postnatal day $10(\mathrm{P} 10)$ to P17. Animals were anesthetized with a mixture of ketamine and xylazine. After decapitation, the brain was transferred into a sucrose-based solution bubbled with $95 \% \mathrm{O}_{2} / 5 \% \mathrm{CO}_{2}$ and maintained at $\sim 3^{\circ} \mathrm{C}$. This solution contained the following (in mM): 248 sucrose, 2 $\mathrm{KCl}, 1 \mathrm{MgCl}_{2}, 1.25 \mathrm{KH}_{2} \mathrm{PO}_{4}, 26 \mathrm{NaHCO}_{3}$, and 10 glucose. Transverse coronal brain slices $(350 \mu \mathrm{M})$ were prepared using a Vibratome (VT1000S; Leica, Nussloch, Germany). Slices were equilibrated with an oxygenated artificial CSF (aCSF) for $>1 \mathrm{~h}$ before transfer to the recording chamber. The slices were continuously superfused with aCSF at a rate of $2 \mathrm{ml} / \mathrm{min}$ (unless noted in the text) containing the following (in $\mathrm{mM}$ ): $113 \mathrm{NaCl}, 3 \mathrm{KCl}, 1 \mathrm{NaH}_{2} \mathrm{PO}_{4}, 26 \mathrm{NaHCO}_{3}, 2.5 \mathrm{CaCl}_{2}, 1 \mathrm{MgCl}_{2}$, and 10 glucose [in $95 \% \mathrm{O}_{2} / 5 \% \mathrm{CO}_{2}$ at room temperature $\left(24-26^{\circ} \mathrm{C}\right)$ ].

Electrophysiological recordings. Brain slices were placed on the stage of an upright infrared-differential interference contrast microscope (BX50WI; Olympus Optical, Tokyo, Japan) mounted on a Gibraltar X-Y table (Zeiss, Oberkochen, Germany) and visualized with a $40 \times$ water immersion objective by infrared microscopy (camera by Dage-MTI, Michigan City, IN). Membrane currents were recorded at room temperature $\left(24-26^{\circ} \mathrm{C}\right.$ ) with an Axopatch 200B patch-clamp amplifier (Axon Instruments, Union City, CA) in the whole-cell configuration (unless otherwise indicated). The external solution contained the following (in $\mathrm{mm}): 113 \mathrm{NaCl}, 3 \mathrm{KCl}, 1 \mathrm{NaH}_{2} \mathrm{PO}_{4}, 26 \mathrm{NaHCO}_{3}, 2.5 \mathrm{CaCl}_{2}, 1 \mathrm{MgCl}_{2}$, and 10 glucose (except as noted) (in 95\% $\left.\mathrm{O}_{2} / 5 \% \mathrm{CO}_{2}\right)$. CNQX $(10 \mu \mathrm{M})$, DL-AP-5 $(50 \mu \mathrm{M})$, and atropine $(500 \mathrm{nM})$ were continuously present in the external solution. The internal solution contained the following (mM): $130 \mathrm{KCl}$ or $\mathrm{CsCl}, 2 \mathrm{MgCl}_{2}, 10$ EGTA, $5 \mathrm{CaCl}_{2}, 10$ HEPES, 1 $\mathrm{Na}_{2} \mathrm{ATP}$, and $0.5 \mathrm{Na}_{2} \mathrm{GTP}$. Pipettes resistance ranged from 2.5 to $4 \mathrm{M} \Omega$.

For perforated patch-clamp recording using gramicidin (Sigma, St. Louis, MO), the pipette tip was filled with an internal solution $(150 \mathrm{ml}$ $\mathrm{KCl}$ and $10 \mathrm{ml}$ HEPES, pH 7.3) and backfilled with the same solution containing gramicidin $(100 \mu \mathrm{g} / \mathrm{ml})$. Access resistance was stable between 20 and $30 \mathrm{M} \Omega$ after $\sim 1 \mathrm{~h}$.

Eliciting monosynaptic postsynaptic currents and detection of miniature postsynaptic currents. For extracellular stimulation, an electrode prepared from "theta $(\theta)$ " glass (World Precision Instruments, Sarasota, FL) filled with extracellular solution was placed close to the recorded neuron. Pairs of stimuli were delivered at $0.1 \mathrm{~Hz}$ (interval of $150 \mathrm{~ms} ; 1 \mathrm{~ms}$; from -20 to $-100 \mu \mathrm{A})$; the paired-pulse modulation ratio is defined as $\left[\left(I_{2}-I_{1}\right) \times\right.$ $100] / I_{1}$. To induce the release of endogenous $\mathrm{ACh}$, burst stimulation $(50 \mathrm{~Hz}$ for $1 \mathrm{~s}$, five times; interval between stimuli, $5 \mathrm{~s}$ ) was applied in the area in which we detected cholinergic cell bodies $(\sim 2-3 \mathrm{~mm}$ from recording site).

Spontaneous miniature postsynaptic currents (mPSCs) were recorded in the presence of tetrodotoxin (TTX) ( $1 \mu \mathrm{M}$; Sigma). Autodetected events with amplitude of more than $-5 \mathrm{pA}$ and rise time of $<3 \mathrm{~ms}$ were also visually examined to correct for noise fluctuation. Analysis of mPSC decay phase was based on the following criteria: (1) single events only (i.e., no multiple events), (2) events having stable baselines $15 \mathrm{~ms}$ before the rise, and (3) smooth transition from 0 current to peak amplitude $[<20 \%$ deviation in $d(\mathrm{pA}) / d t)$ during rise]. All data were stored for off-line analysis on a personal computer with a Pentium III or IV processor after being filtered at $5 \mathrm{kHz}$ by the Axopatch 200B amplifier. Analysis used pClamp8 (Axon Instruments) and Mini analysis 5.0 (Synaptosoft, Decatur, GA).

Immunocytochemical staining. The recorded neurons that were relo- cated and processed for subsequent immunohistochemical analyses were injected with Alexa-Fluor 488 (Invitrogen, Carlsbad, CA). The brain slices were then fixed and remounted, and cryostat sections were prepared as delineated below.

For routine immunocytochemical studies, P15 mice under deep anesthesia were perfused with $4 \%$ formaldehyde in PBS. The entire brain was dissected and postfixed intact for $3 \mathrm{~h}$ in $4 \%$ formaldehyde/4\%sucrose (PBS) and then equilibrated in $30 \%$ sucrose (PBS). Tissue was embedded in OCT, frozen, and sliced in $14 \mu \mathrm{m}$ sections. Brain sections were incubated with $0.3 \%$ Triton X-100 (PBS) for 30 min, with $8 \%$ donkey serum (in $0.3 \%$ Triton X-100, PBS) for 30 min to block nonspecific binding and again with $0.3 \%$ Triton X-100 (PBS) for another $30 \mathrm{~min}$ at room temperature. Primary antibodies against MCH (1:200; Santa Cruz Biotechnology, Santa Cruz, CA) and vesicular ACh transporter (VAT) (1:500, Sigma; or 1:500, Chemicon, Temecula, CA) and/or $\alpha$-bungarotoxin $\alpha$ BgTx conjugated to fluroprobe (Alexa-Fluor 488) were incubated overnight at $4^{\circ} \mathrm{C}$. The brain sections were incubated with $0.3 \%$ Triton X-100 (PBS) for $10 \mathrm{~min}$, rinsed twice with PBS, and reincubated for $2 \mathrm{~h}$ at room temperature in secondary antibodies FITC-conjugated anti-rabbit IgG for VAT and a rhodamine-conjugated anti-goat IgG for $\mathrm{MCH}$ (diluted 1:200; both from Jackson ImmunoResearch, West Grove, PA). Brain slices were rinsed twice in PBS and mounted onto slides.

Prenatal and perinatal exposure to nicotine. Pregnant females at $14 \mathrm{~d}$ after mating were given nicotine through the drinking water with sucrose (2\%) and nicotine $(200 \mu \mathrm{g} / \mathrm{ml})$ or with sucrose alone (control group) throughout the period of pregnancy and lactation. Based on other reports using this technique in mice, steady-state levels of nicotine achieved under these conditions are $\sim 175 \mathrm{ng} / \mathrm{ml}$ in pup blood (Pauly et al., 2004).

Single cell reverse transcription-PCR. Single-cell samples were collected from brain slice preparations via aspiration into the patch pipette. The initial reverse transcription (RT) reaction was conducted after pressure ejection of the single-cell samples into freshly prepared RT mix A solution (20 U of RNase OUT, $300 \mathrm{ng}$ of random primers, $0.5 \% \mathrm{NP}-40$, and RNase free water). Samples were sonicated in a total volume of $10 \mu \mathrm{l}$ at $4^{\circ} \mathrm{C}$ for $5 \mathrm{~min}$ and then incubated for $3 \mathrm{~min}$ at $65^{\circ} \mathrm{C}$ before addition of 10 $\mu$ RT mix B (500 $\mu \mathrm{M}$ dNTP, $1 \times$ RT buffer, $5 \mathrm{~mm} \mathrm{MgCl}_{2}, 10 \mathrm{~mm}$ DTT, and $200 \mathrm{U}$ of Superscript II 1). The tubes were incubated at $25^{\circ} \mathrm{C}$ for 5 min, at $42^{\circ} \mathrm{C}$ for $1 \mathrm{~h}$, and at $65^{\circ} \mathrm{C}$ for $10 \mathrm{~min}$.

Each cDNA sample obtained was split into two aliquots, one for analysis of $\mathrm{MCH}$ transcripts and the other for analysis of neuronal enolase. Two rounds of amplification were done for the detection of MCH transcripts and one round of amplification for the analysis of neuronal enolase. In the first amplification (final $50 \mu \mathrm{l}$ ), the reaction mixture contained $10 \mu \mathrm{l}$ of cDNA, $1 \times$ PCR buffer with $\mathrm{Mg}^{2+}$ (Roche Products, Indianapolis, IN), $0.2 \mathrm{~mm}$ dNTP, $0.1 \mu \mathrm{M}$ of each primer, and $2 \mathrm{U}$ of Taq polymerase (Roche Products). For the second amplification, the reaction mixtures contained $3 \mu \mathrm{l}$ of the first-round PCR product, $1 \times$ PCR buffer with $\mathrm{Mg}^{2+}$ (Roche Products), $0.5 \mathrm{~mm}$ dNTP, $1 \mu \mathrm{M}$ of each primer, $1 \mathrm{M}$ of Betaine (Sigma), and $2 \mathrm{U}$ of Taq polymerase in a final volume of $30 \mu \mathrm{l}$. After denaturation by $3 \mathrm{~min}$ at $94^{\circ} \mathrm{C}$, the target cDNAs were amplified by 35 cycles $\left(94^{\circ} \mathrm{C}, 30 \mathrm{~s} ; 60^{\circ} \mathrm{C}, 30 \mathrm{~s} ; 72^{\circ} \mathrm{C}, 30 \mathrm{~s}\right.$, followed by $10 \mathrm{~min}$ at $\left.72^{\circ} \mathrm{C}\right)$. As positive control, $1 \mathrm{ng}$ of brain RNA was subjected to RT-PCR in parallel with the single-cell samples. After amplification, the PCR products (532 bp for enolase and $220 \mathrm{bp}$ for $\mathrm{MCH}$ ) were analyzed on $2 \%$ agarose gels. The primers used were as followed: $\mathrm{MCH}$ sense, $5^{\prime}$ CAGCTTCCAAGTCCATAAGG-3'; MCH antisense, 5' - AGTGGCAGCCCGTGAGTTAC-3'; enolase sense, 5'-GCTTTGCCCCCAATATCCTG-3'; enolase antisense, 5' -CACAGTCCGACGACAAGATC-3'. The primers were purchased from Invitrogen.

\section{Results}

\section{Basic characteristics of $\mathrm{LH}$ neurons studied}

This report is based on recordings from $>300$ neurons within a $200 \mu \mathrm{m}$ radius, lateral to the fornix in acute slices of hypothalamus from WT and $\alpha 7 \mathrm{nAChR}(-/-)$ mice. We first examined basic electrophysiological features of perifornical (PF) LH neurons to assess the properties of immunopositive $\mathrm{MCH}$ neurons within this area. Brief pulses (400 ms) of hyperpolarizing and 
A
Type 1
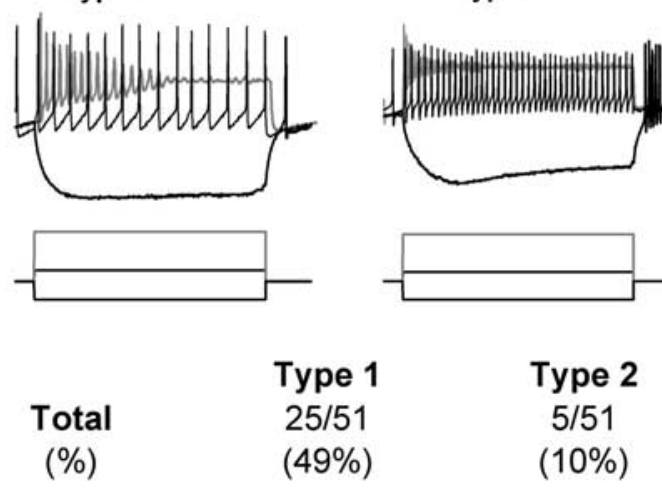

$\mathrm{MCH}+$

(\%)

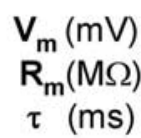

B

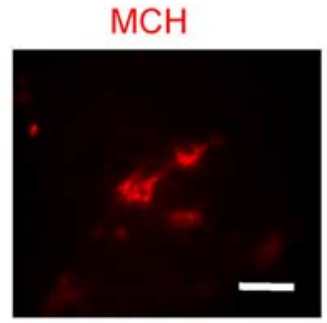

$16 / 21$

(76\%)

$-55.4 \pm 0.9$
$438 \pm 46$
$20 \pm 1.3$

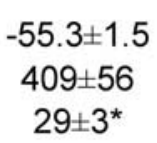

Type 3

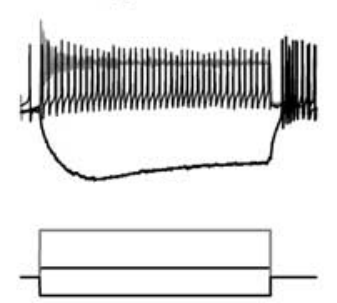

Type 2

(10\%)

$1 / 21$

(5\%)

(24\%)

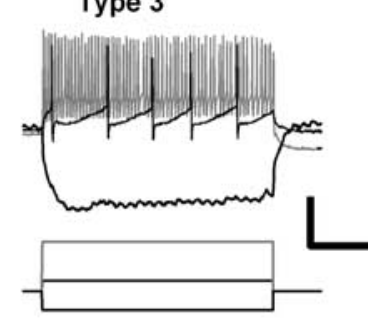

Type 3

16/51

(31\%)
$-59.4 \pm 1^{*}$

$413 \pm 41$

$18 \pm 2$

C

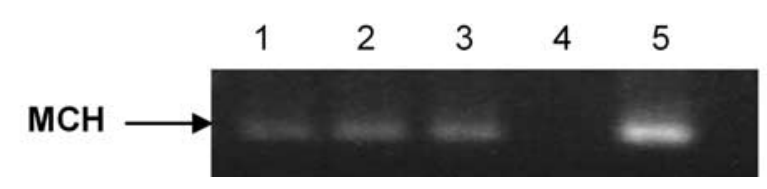

Figure 1. Characteristics of PF LH neurons. A, Electrical properties of PF LH neurons. PF LH neurons were classified into three groups based on the active and passive membrane properties. Top, Responses of $L H$ neurons to three different depolarizing and hyperpolarizing current steps from the resting membrane potential level in current-clamp mode. Type 1 neurons typically displayed moderate spike accommodation in response to sustained depolarization and were multipolar. Type 2 neurons were distinguished by the presence of a hyperpolarization-activated current and a more prolonged membrane time constant. Type 3 neurons showed tonic firing in response to direct depolarization and had a more hyperpolarized resting membrane potential than type 1 or 2 neurons. Bottom, Summary of the basic characteristics of PF LH neurons. The majority of MCH-positive neurons in PF LH are type 1. Asterisks represent a significant difference between groups $(p<0.05)$. $\mathrm{V}_{\mathrm{m}^{\prime}}$ Resting membrane potential; $\mathrm{R}_{\mathrm{m}}$, input resistance; $\tau$, membrane time constant. Calibration: $50 \mathrm{mV}, 0.65 \mathrm{nA}, 100 \mathrm{~ms}$. $\boldsymbol{B}$, After electrophysiological characterization, neurons were injected with dye for relocalization. Example of a type 1 neuron (green) that was immunostained with an antibody to MCH (red). Scale bar, $20 \mu \mathrm{m}$. C, Single-cell RT-PCR was used to assess the expression of MCH and neuronal enolase in 25 cells as typically examined in the PF LH. Representative results are shown. Lane 5 is a positive control (total brain mRNA). Lanes 1-3 are positive for both neuronal enolase and MCH mRNA. The cell in lane 4 was neuronal enolase positive but MCH negative.

depolarizing currents (from -200 to $400 \mathrm{pA}$; step, $50 \mathrm{pA} ; 400 \mathrm{~ms}$ ) were applied to the patch pipette with the neuron in currentclamp configuration. The majority of PF LH neurons studied in this manner could be grouped into three classes based on the apparent shape of the cell body and the neuritic arbor confirmed from post hoc analysis of dye (Alexa-Fluor 488)-filled cells and on the passive and active membrane properties (Fig. 1A). Among the population of recorded neurons, direct injection of depolarizing current elicited firing with moderate accommodation in $\sim 50 \%$ of neurons (Fig. 1A). This first group, referred to as type 1 neurons, is typically multipolar. Type 2 neurons, which comprised $\sim 10 \%$ of the population studied, were distinguished by a transient hyperpolarization-activated current with a more prolonged time constant than type 1 or 3 neurons. Type 3 neurons (31\%) displayed continuous firing without spike accommodation during a direct depolarizing pulse and were significantly more hyperpolarized at rest membrane potential than either type 1 or type 2 (Fig. $1 \mathrm{~A}$ ).

A subset of the electrophysiologically characterized neurons $(n=51)$ were successfully relocated after the recording session and examined for immunofluorescent staining with an antibody to $\mathrm{MCH}$. Comparison of the electrophysiological profiles, location, shape, and immunohistochemical data revealed that the majority of neurons with a type 1 profile were positively stained for MCH (Fig. 1B). Overall, $43 \%$ of the neurons that were electrophysiologically characterized and relocalized after immunocytochemical analysis were $\mathrm{MCH}$ positive, with the majority (76\%) of these $\mathrm{MCH}$-positive neurons conforming to type 1 characteristics. We find a similar fraction of PF LH neurons to be $\mathrm{MCH}$ positive by single-cell PCR analysis (Pakkanen et al., 2005). Previous reports from other laboratories have associated the bipolar morphology and tonic firing rate profile as seen in our type 3 neurons with orexin-expressing cells in $\mathrm{LH}$ slices (Li et al., 2002; Eggermann et al., 2003; Gao et al., 2003). Also, van den Pol and colleagues demonstrated that $\mathrm{MCH}-$ positive neurons in culture, as well as in brain slice preparations, show spikefrequency adaptation with sustained depolarization and responses to hyperpolarizing current that are similar to that of our type 1 neurons (Gao et al., 2003; van den Pol et al., 2004). In addition, we collected samples from 25 individual cells that were within the PF LH and selected based on the criteria delineated above. Single-cell RT-PCR was used to assess the expression of $\mathrm{MCH}$ and neuronal enolase (Fig. 1C). Together, it appears that the $\mathrm{MCH}$ expressing neurons are readily distinguished from at least two other major classes of neurons within the PF LH, by electrophysiological and morphological criteria.

\section{Glucose and nicotine sensitivity of GABAergic inputs to PF LH neurons}

Previous in vitro studies demonstrated that GABAergic transmission among LH neurons was modulated by nAChR activation (Jo and Role, 2002). To pursue these observations in the more intact brain slice preparations, we examined nAChR-mediated effects 
A

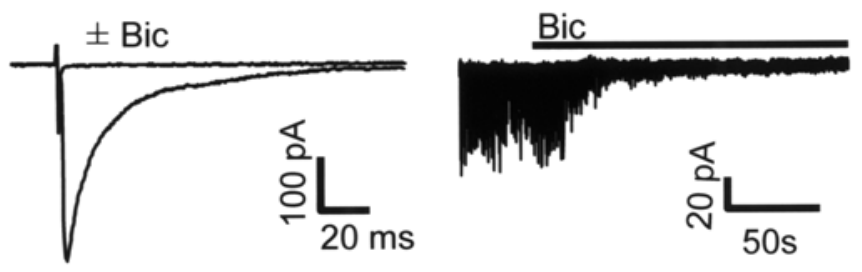

B

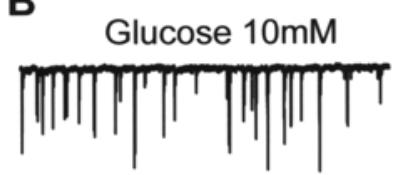

Glucose $1 \mathrm{mM}$

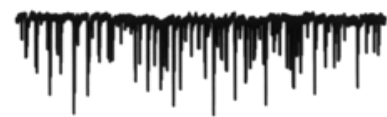

Glucose $10 \mathrm{mM}$
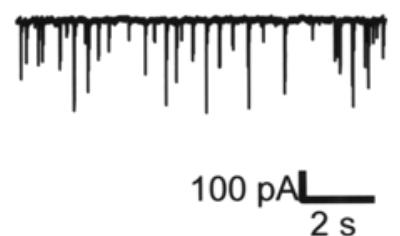

C

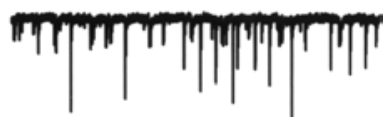

Glucose $1 \mathrm{mM}$

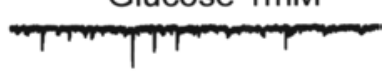

Glucose $10 \mathrm{mM}$

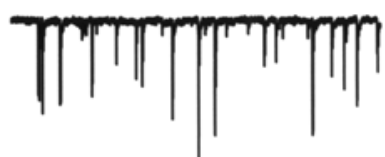

$50 \mathrm{pAL}$

Figure 2. Properties of presynaptic GABAergic inputs to PF LH neurons. A, All recordings shown are in the presence of CNQX and DL-APV to block glutamatergic transmission. The addition of the $\mathrm{GABA}_{\mathrm{A}}$ receptor antagonist bicuculline (Bic; $10 \mu \mathrm{m}$ ) completely blocks both the evoked and spontaneous synaptic currents recorded, consistent with their being mediated by $G A B A_{A}$ receptors. $B, C, G A B A e r g i c$ inputs are sensitive to the concentration of external glucose. Lowering external [glucose] increased the frequency of GABAergic sIPSCs in approximately half of the neurons tested $(\boldsymbol{B})$ and depressed GABAergic transmission in $\sim 30 \%$ of neurons $(\boldsymbol{C})$.

on GABAergic transmission in slice recordings with a mixture of NMDA and AMPA receptor blockers. Under these conditions, all stimulus evoked, spontaneous, and TTX-resistant (miniature) postsynaptic currents detected are sensitive to bicuculline (10 $\mu \mathrm{M})$, consistent with our monitoring GABAergic transmission in isolation ( $n=16$ neurons) (Fig. $2 A$ ).

We next assessed how the GABAergic inputs to PF LH neurons respond to peripheral and/or exogenous signals, including glucose and nicotine. If the GABAergic input to PF LH neurons participates in appetite-related neural circuitry, then, based on previous literature, we expect certain profiles of glucose response characteristics of the synaptic transmission in PF LH (Liu et al., 2001; Song et al., 2001; Wang et al., 2004). In these experiments, the external concentration of glucose was lowered from 10 to 1 mM. Lowering [glucose] $]_{\text {ext }}$ resulted in modulation of GABAergic transmission within $<1$ min of switching the perfusion media in $\sim 70 \%$ of the neurons tested [Fig. $2 B$ ( $n=7$ of 15 positively modulated), $C$ ( $n=4$ of 15 neurons negatively modulated)]. Thus, the majority of the PF LH neurons studied appear to receive GABAergic inputs that are effected by changes in [glucose]$_{\text {ext }}$, consistent with their potential involvement in feedingrelated circuits (Song et al., 2001; Wang et al., 2004).

\section{Cholinergic projections within the $\mathrm{LH}$}

Having identified a population of PF neurons that receive both glucose- and nicotine-sensitive GABAergic inputs, we next examined whether locally released ACh might modulate synaptic ex-

citability via nAChRs. If endogenous ACh normally participates in the regulation of PF LH synapses, then cholinergic inputs should be detectable in mouse LH (Rao et al., 1987; Tago et al., 1987; Woolf, 1991; Oh et al., 1992). Visualization of immunoreactivity for VAT demonstrated positive staining in fiber-like structures throughout the LH (Fig. $3 B$ ). In addition to these cholinergic nerve processes, we also detected numerous VATpositive cell bodies in the area adjacent to the optic tract, along the LH/zona incerta border and near the substantia innominata, as observed previously in other rodent studies (Tago et al., 1987; Grove, 1988; Woolf, 1991).

Examination of the $\mathrm{LH}$ area with antibody probes for $\mathrm{MCH}$ (Fig. $3 A, C$ ) revealed $\mathrm{MCH}$-positive neurons in a broad swath across the lateral and more medial regions of the lateral hypothalamic area. $\mathrm{MCH}$-positive neurons were particularly plentiful in the PF area of the LH, in which both our recording studies and immunohistochemical identifications of cholinergic fibers were conducted. Figure 3C shows higher-magnification views of double immunostaining of a typical PF LH area studied with antibodies against both VAT and MCH. VAT-positive fibers appear in close proximity with $\mathrm{MCH}$-positive as well as $\mathrm{MCH}$-negative neurons.

Having confirmed the existence of endogenous sources of ACh to PF LH neurons, we then tested whether the effect of increasing the local concentration of ACh could alter the overall suprathreshold activity of PF LH neurons. These initial recordings in current-clamp configuration used perforated patch with gramicidin to maintain intracellular $\mathrm{Cl}^{-}$. Based on results of previous studies of nicotine application in in vitro preparations of LH (Jo and Role, 2002), we sought to assess the potential role of $\mathrm{nAChRs}$ in the modulation of GABAergic inputs in vivo and therefore included blockers of both glutamate receptors and muscarinic AChRs. Under these recording conditions in acute LH slice, we observed that increasing the external concentration of ACh $\left(\uparrow[\mathrm{ACh}]_{\text {ext }}\right)$ decreased the firing rate of PF LH neurons at resting membrane potential (Fig. 3D). The observed decrease in firing rate of PF LH neurons with elevated $[\mathrm{ACh}]_{\text {ext }}$ could be attributable to an ACh-induced increase in inhibitory tone and/or the activation of outward currents in the postsynaptic neuron. Subsequent studies attempted to discern the mechanisms by which endogenous ACh might affect the synaptic excitability of PF LH neurons in more detail.

We next tested whether the PF LH synapses in these brain slice preparations, like those we had studied previously in dispersed cell culture, were modulated by direct activation of nAChRs (Jo and Role, 2002). Nicotine (0.5-1 $\mu \mathrm{M})$ increased the amplitude of evoked IPSCs (eIPSCs) (eIPSCs plus nicotine, $217 \pm 10 \%$ of control; $n=5$ of 10) (Fig. $3 E$ ) and enhanced the frequency of spontaneous IPSCs (sIPSCs) (sIPCS plus nicotine, $178 \pm 14 \%$ of control; $n=5$ of 10 ) (Fig. $3 E$ ). Thus, GABAergic inputs to PF LH neurons within the intact LH slice are sensitive to nicotine.

\section{Facilitation of spontaneous and evoked GABAergic} transmission by endogenous ACh

We next pursued the mechanisms of potential physiological contributions of endogenous activation of $\mathrm{nAChR}$ on GABAergic inputs to PF LH neurons using two different approaches. Synaptic transmission was monitored in voltage clamp, and we elevated the $[\mathrm{ACh}]_{\text {ext }}$ by either inhibition of acetylcholinesterase (AChEI) (Figs. 4, 5) or electrical stimulation in areas of vesicular ACh transporter-positive cell bodies (Fig. 6).

AChE inhibitors vary in their relative affinity, off rate, and selectivity for the AChE (Hodge et al., 1992). In preliminary 

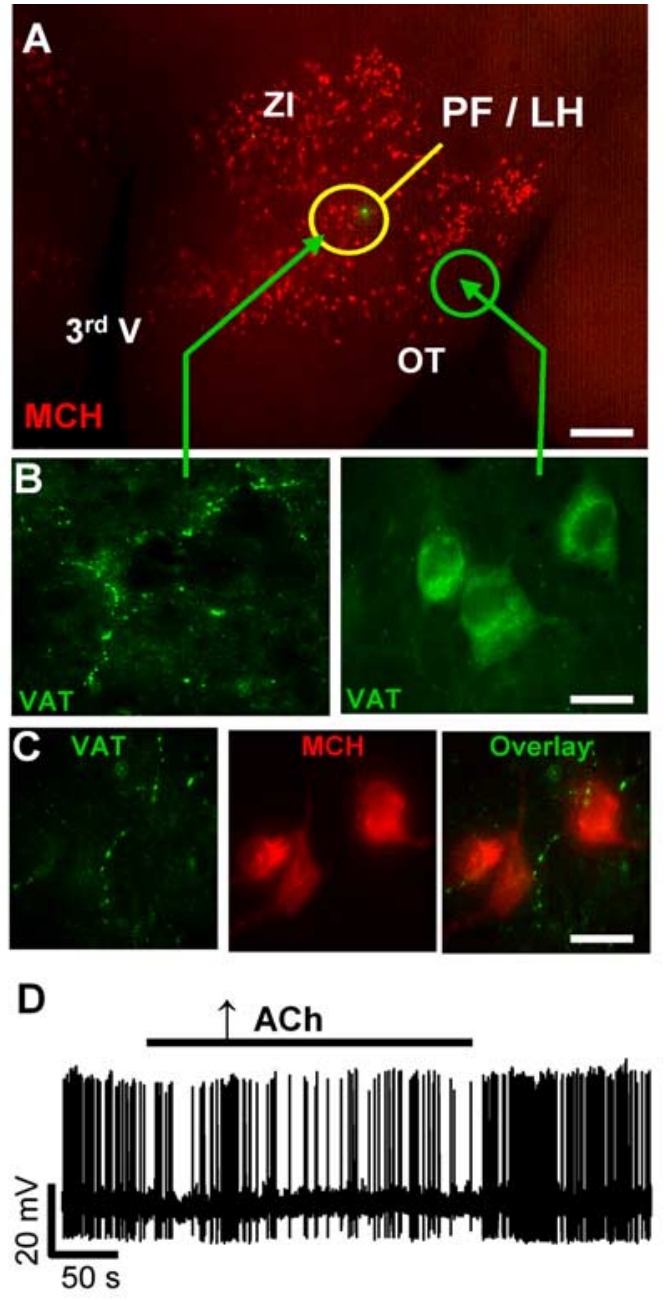

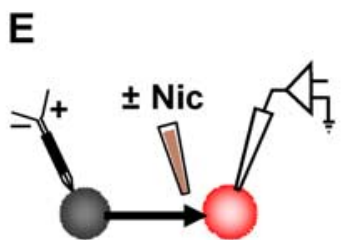

PF LH
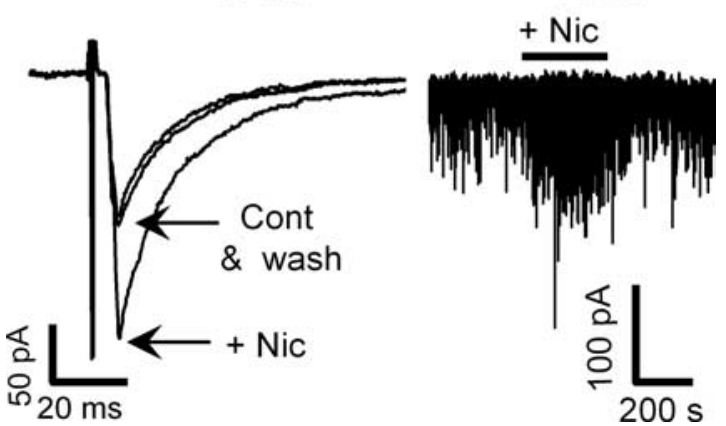

Figure 3. Presence of cholinergic neurons and fibers within the mouse LH. A, MCH-positive neurons (red) are distributed throughout the lateral hypothalamus. The yellow circle indicates the approximate recording area within the PF LH area in all studies (example of a recorded neuron injected with FITC). The green circle indicates the region of cholinergic neuronal cell bodies along the lateralmost border of the $\mathrm{LH}$ at which electrodes were placed to stimulate endogenous cholinergic pathways (see Fig. 6). Scale bar, $300 \mu \mathrm{m}$. B, VAT-positive cell bodies (green; right) are located within the LH, along the LH border close to the optic tract (OT) and in the neighboring zona incerta (ZI). Cholinergic fibers are evident in the PF LH (green; left). Scale bar, $15 \mu \mathrm{m}$. C, VAT-positive immunostained processes appear to contact MCH-positive cell bodies in the PF LH area. Scale bar, $15 \mu \mathrm{m}$. D, In the perforated patch-clamp recording using
A
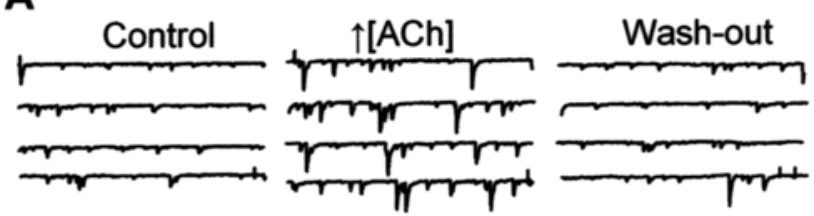

B
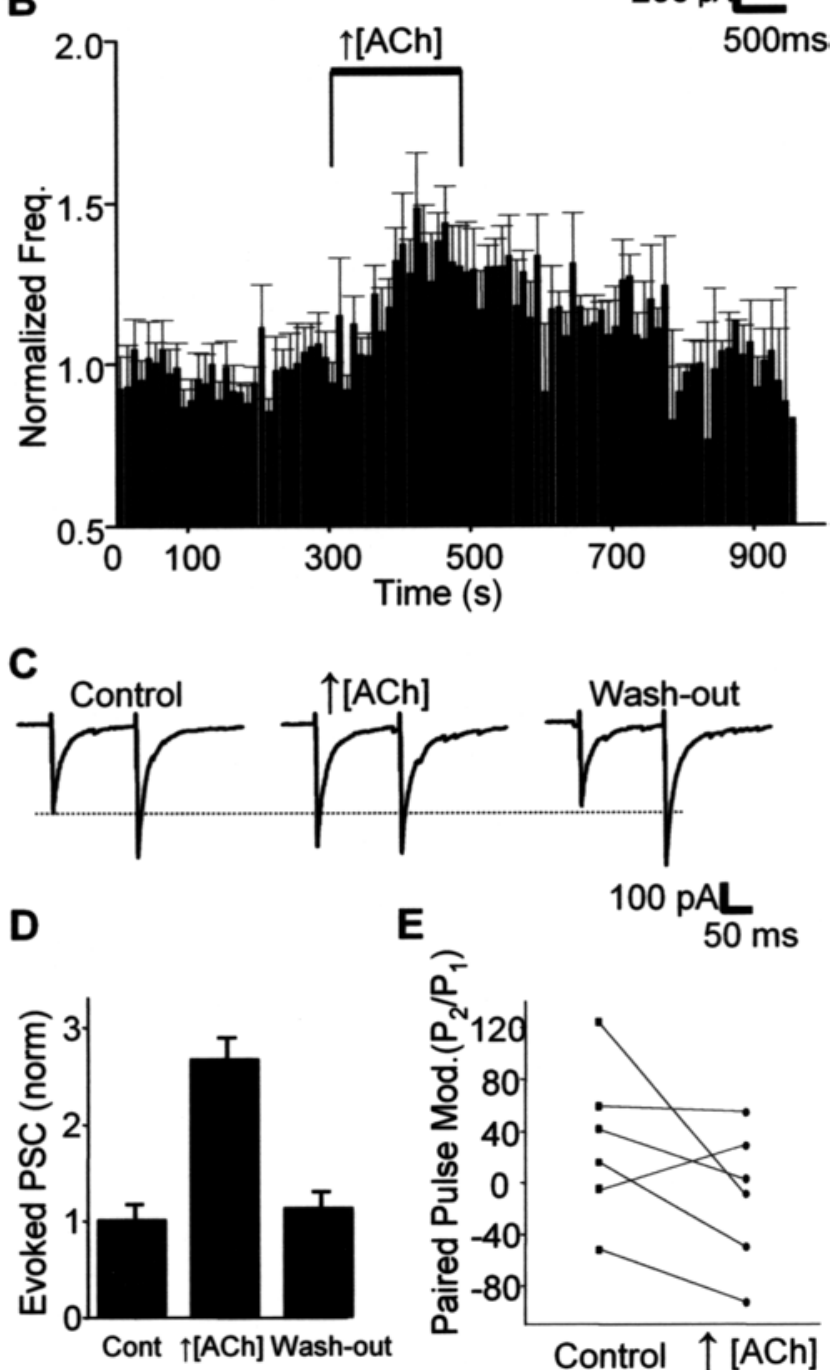

$50 \mathrm{~ms}$

Figure 4. Increasing extracellular acetylcholine levels by AChE inhibition modulates both the spontaneous and evoked GABAergic transmission to PF LH neurons. $A, B$, Facilitation of spontaneous synaptic transmission by elevated $[A C h]_{\text {ext }}$. Sample current traces showing spontaneous GABAergic IPSCs recorded at a holding potential of $-70 \mathrm{mV}$ before, during, and after

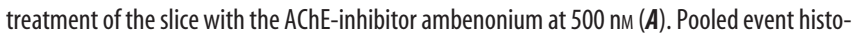
gram from six separate experiments showing the time course of synaptic current frequency recorded in PF $L H$ neurons before, during, and after treatment of the slice with ambenonium (B). Control sIPSC frequency averaged $1.3 \pm 0.4 \mathrm{~Hz}$ in this series. C, D, Facilitation of evoked synaptic transmission by elevated $[\mathrm{ACh}]_{\text {ext }}$. Representative recordings of evoked GABAergic IPSCs at a holding potential of $-70 \mathrm{mV}$ before, during, and after treatment of the slice with ambenonium ( $500 \mathrm{~nm} ; \mathbf{C}$ ). Each set of traces is the average of five consecutive stimulus pairs under each of the indicated conditions. $\boldsymbol{E}$, The extent of paired-pulse modulation was also affected by elevated $[\mathrm{ACh}]_{\text {ext }}$ consistent with involvement of a presynaptic mechanism.

$\leftarrow$

gramicidin to keep the $\mathrm{Cl}^{-}$concentration intact, an increase of ACh concentration by inhibiting AChE decreases firing rate at the resting membrane potential. $V_{\mathrm{m}}$ of $-56 \mathrm{mV}$. $E$, Direct application of nicotine facilitates GABAergic transmission at most PF LH synapses. Top, Schematic diagram of recording configuration. Bottom, Nicotine (Nic; $1 \mu \mathrm{M}$ ) increased the amplitude of stimulus-evoked IPSCs (left) as well as increasing the frequency of spontaneous IPSCS (right). 
A1
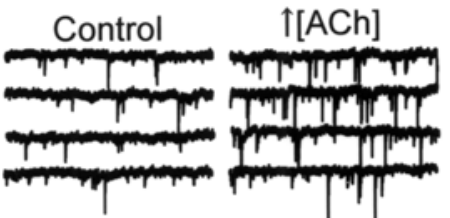

Wash out

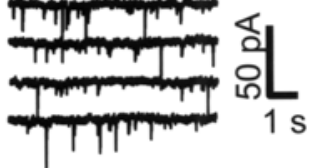

A2

A3
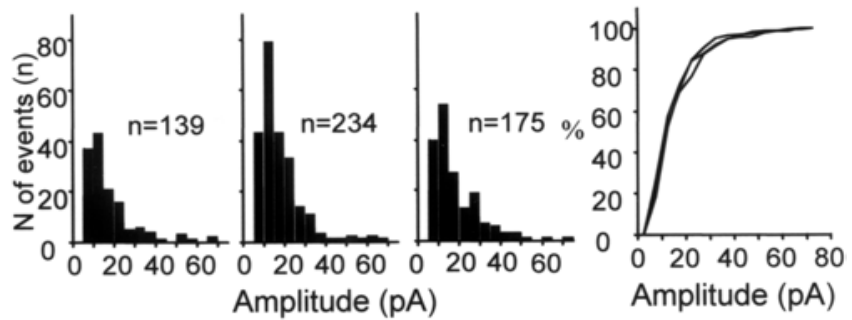

B

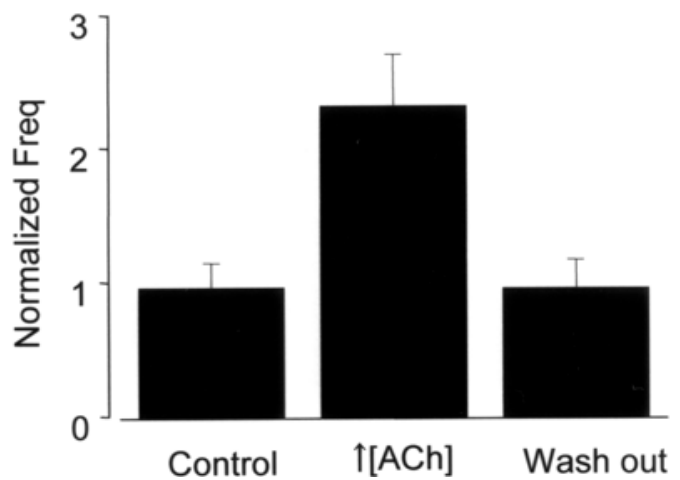

Figure 5. Increasing the ambient concentration of ACh increases the frequency of miniature IPSCs at LH synapses. A1-A3, Enhancement of the frequency without change in amplitude of TTX-resistant miniature GABAergic IPSCs by elevated $[\mathrm{ACh}]_{\text {ext }}$. Sample current traces showing spontaneous miniature GABAergic IPSCs recorded at a holding potential of $-70 \mathrm{mV}$ before, during, and after treatment of the slice with the AChE inhibitor ambenonium at $500 \mathrm{~nm}(\boldsymbol{A 1})$. Neither the amplitude distribution nor the mean amplitude of mIPSCs was significantly affected $(\boldsymbol{A} 2, \boldsymbol{A} 3) . \boldsymbol{B}$, Increased $[A C h]_{\text {ext }}$ enhances the frequency of GABAergic mIPSCs. Summary of spontaneous miniature synaptic current frequency data from all experiments $(n=14)$. Results obtained in the presence or absence of atropine $(1 \mu \mathrm{m})$ were indistinguishable, consistent with modulation via nicotinic rather than muscarinic AChRs. Control mIPSC frequency averaged $0.6 \pm 0.1 \mathrm{~Hz}$ in this series.

work, we examined galanthamine as well as ambenonium effects on synaptic transmission. We chose ambenonium for subsequent studies because of its higher selectivity for AChE per se. In another series of experiments, we used high-frequency extracellular stimulation $(50 \mathrm{~Hz})$ of the $\mathrm{LH}$ area that includes cholinergic cell groups (Fig. 3) (Rao et al., 1987; Tago et al., 1987; Woolf, 1991; Oh et al., 1992). In all cases, GABAergic transmission was isolated by inclusion of glutamate receptor blockers (see Materials and Methods).

Application of the AChEI ambenonium at 100-500 nM to LH slices increased the frequency of sIPSCs (Fig. $4 A, B$ ). Initial experiments revealed that increased $[\mathrm{ACh}]_{\mathrm{ext}}$ resulted in an enhancement of GABAergic sIPSCs via activation of nAChRs in both the presence and absence of muscarinic antagonists. In all subsequent experiments, the contribution of nAChRs was isolated from that of nAChRs by inclusion of atropine $(0.5-1 \mu \mathrm{M})$ (Zwart et al., 1999). Increased [ACh $]_{\text {ext }}$ facilitated spontaneous GABAergic IPSCs by $158 \pm 1 \%$ compared with control; there were no significant changes in the amplitude of these synaptic
A
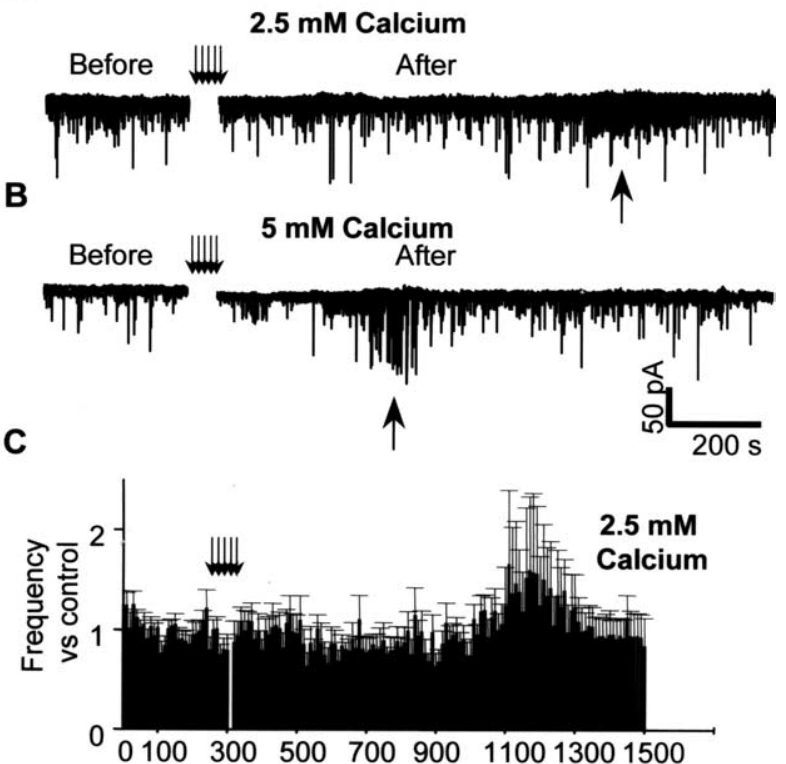

D
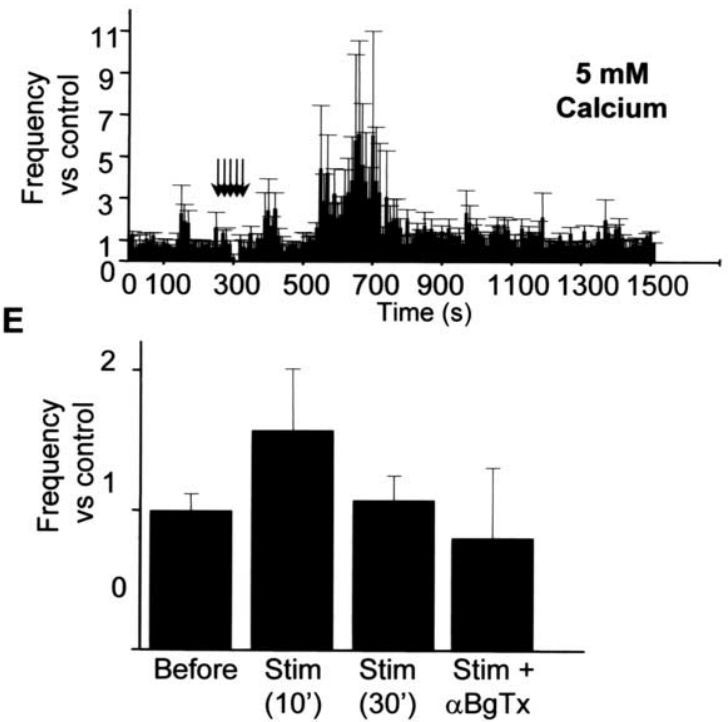

Figure 6. Extracellular stimulation of local cholinergic neurons triggers $n A C h R$-dependent facilitation of GABAergic transmission. $A$, Extracellular stimulation of nearby cholinergic neurons facilitates spontaneous GABAergic synaptic transmission. Sample current traces showing spontaneous GABAergic IPSCs recorded at a holding potential of $-70 \mathrm{mV}$, before and after extracellular stimulation within the area of cholinergic cell bodies (as indicated in Fig. $3 A ; 50 \mathrm{~Hz}$, $1 \mathrm{~s}$ for 5 times; $5 \mathrm{~s}$ interstimulus interval; $2.5 \mathrm{~mm}$ calcium). $\boldsymbol{B}$, Modulation of spontaneous synaptic transmission by stimulation of cholinergic neurons in the presence of $5 \mathrm{~mm}$ calcium. Sample current traces showing spontaneous GABAergic IPSCs recorded at a holding potential of $-70 \mathrm{mV}$, before and after stimulus burst. C, Pooled event histogram from 15 separate experiments showing the time course of synaptic current frequency recorded in PF LH neurons before, during, and after stimulation within the area of cholinergic cell bodies in $\mathrm{LH}$ in the presence of $2.5 \mathrm{~mm}$ calcium. The nAChR-mediated increase in GABAergic synaptic transmission occurs at $\sim 10-15$ min after the stimulus burst. $\boldsymbol{D}$, Extracellular stimulation of cholinergic cell bodies is more efficacious in the modulation of spontaneous GABAergic synaptic transmission in the presence of $5 \mathrm{~mm}$ calcium. Pooled event histogram from five separate experiments showing the time course of synaptic current frequency in the presence of $5 \mathrm{~mm}$ calcium. The nAChR-mediated increase in GABAergic synaptic transmission reaches 10 times the baseline frequency and occurs at $\sim 3-5$ min after the stimulus burst. $E$, Stimulation of cholinergic neurons induces modulation of GABAergic transmission that is mediated by the activation of nAChRs. Summary of synaptic current frequency data from all experiments examining the pharmacology of burst stimulus-evoked modulation. Mecamylamine (data not shown) as well as $\alpha$ BgTx completely block stimulus burst-induced facilitation of GABAergic transmission. Control sIPSC frequency averaged $1.8 \pm 0.8 \mathrm{~Hz}$ in this series. 
currents (control, $-53 \pm 8 \mathrm{pA}$; plus AChEI, $-56 \pm 7 \mathrm{pA} ; n=6$ ). Approximately half of the GABAergic inputs to type 1 neurons were modulated by increased $[\mathrm{ACh}]_{\mathrm{ext}}$ as measured by assays of spontaneous IPSCs $(n=10)$. Treatment with AChEI resulted in facilitation of spontaneous GABAergic transmission in all neurons in which $1 \mathrm{~mm}$ glucose decreased the frequency of sIPSCs ( $n=4$ of 4 neurons). In neurons in which lowering external glucose concentration caused a facilitation of GABAergic transmission, increasing $[\mathrm{ACh}]_{\text {ext }}$ was without effect $(n=0$ of 7 neurons). These data are consistent with the interpretation that $\mathrm{ACh}$ modulates a specific subset of glucose-sensitive GABAergic synapses in the PF LH.

We next examined the effects of increased $[\mathrm{ACh}]_{\mathrm{ext}}$ on stimulus-evoked GABAergic synaptic transmission: evoked IPSCs are also potently modulated by manipulation of $[\mathrm{ACh}]_{\text {ext }}$ (Fig. 4C-E). Paired-pulse stimuli (interval, $150 \mathrm{~ms}$ ) in the area of inputs to PF LH neurons elicited robust eIPSCs. When pairedpulse stimulation of GABAergic input to PF LH was coupled with increased $[\mathrm{ACh}]_{\mathrm{ext}}$, the amplitude of the evoked IPSCs was significantly increased in $\sim 30 \%$ of neurons tested ( 6 of 21 neurons; ambenonium, $500 \mathrm{~nm}$ ) (Fig. 4C-E). Treatment with AChEI not only enhanced the average amplitude of eIPSCs $(243 \pm 42 \%$ of control; $n=6$ ) but also changed the ratio of paired-pulse modulation (Fig. $4 E$ ). In contrast, the decay time constant of eIPSCs was not affected (control, $16 \pm 2 \mathrm{~ms}$; ambenonium, $17 \pm 2 \mathrm{~ms}$; $n=6$ cells; $p>0.05)$. These data are consistent with the interpretation that the enhancement of GABAergic eIPSCs is attributable to nAChR-induced changes in presynaptic function.

Although ACh can facilitate GABAergic transmission, the modulation is independent of superthreshold activity (Fig. 5). In the presence of TTX $(1 \mu \mathrm{M})$, augmentation of $[\mathrm{ACh}]_{\mathrm{ext}}$ elicited a reproducible increase in the frequency of miniature IPSCs (mIPSCs) within $\sim 1$ min of treatment with AChEI. Neither the amplitude distribution nor the mean amplitude or decay time constants of the mIPSCs were affected by $[\mathrm{ACh}]_{\text {ext }}(n=8$; mean amplitude: control, $25 \pm 3 \mathrm{pA}$; plus ambenonium, $23 \pm 4 \mathrm{pA}$; decay time constant: control, $13 \pm 2 \mathrm{~ms}$; plus ambenonium, $13.5 \pm 2 \mathrm{~ms}$; data not shown) (Fig. $5 A$ ). The mean increase of the mIPSC frequency is $247 \pm 58 \%$ of control ( $n=8$ of 14 ) (Fig. $5 B$ ). Together, our data indicate that an increase of ACh in the synaptic area elicited by inhibition of AChEI is sufficient to produce significant facilitation of ongoing GABAergic synaptic transmission. In view of results obtained in both paired-pulse stimulation experiments and in assays of TTX-resistant spontaneous IPSCs, as well as in the presence and absence of muscarinic receptor antagonists (data not shown), we suggest that the AChRmediated modulation of GABAergic inputs to type $1, \mathrm{LH} / \mathrm{MCH}$ neurons involves nAChR-activated changes in presynaptic aspects of GABA transmission.

A diffuse or nondirected release of ACh may be the principal manner through which cholinergic terminals influence neuronal activity in the CNS (Descarries et al., 1997). Previous studies propose that $\mathrm{ACh}$ can diffuse from cholinergic en passant-type terminals, thereby exerting its effects at some distance from the release sites by "volume transmission." To explore potential physiological influences of endogenous cholinergic neurons on the PF LH circuit, we examined the effects of high-frequency stimulation of local cholinergic cell bodies. The stimulation electrode was typically placed $\sim 3 \mathrm{~mm}$ from the PF LH neurons selected for recording (as indicated by green circle in Fig. $3 A$ ). With the high-frequency extracellular stimulation paradigm of $50 \mathrm{~Hz}$, $1 \mathrm{~s}$ for five times, with an interstimulus interval of $5 \mathrm{~s}$ (see Materials and Methods), we detected an increase in the frequency of
sIPSCs in 38\% of PF LH neurons tested in slices bathed in $2.5 \mathrm{~mm}$ $\mathrm{Ca}^{2+}$ containing aCSF ( 15 of 39 neurons; average enhancement, $156 \pm 44 \%$ of control; baseline frequency, $2.2 \pm 0.7 \mathrm{~Hz}$; mean amplitude: control, $38 \pm 7$ pA; after, $40 \pm 7$ pA; $p>0.05$ ) (Fig. $6 A, C)$. A second period of stimulation was also routinely effective in reproducing the observed facilitation of GABAergic transmission (data not shown). Nicotinic ACh receptor antagonists mecamylamine and $\alpha \operatorname{BgTx}(1 \mu \mathrm{M} ; n=5$ and $50 \mathrm{nM} ; n=4$, respectively) inhibited the facilitation of GABAergic transmission induced by the stimulus burst (Fig. 6E), consistent with the notion that the electrical stimulation induced the release of endogenous ACh, which then enhanced GABA release by activation of nAChRs.

We next examined the effects of applying the same extracellular stimulation paradigm in the presence of $5 \mathrm{~mm}\left[\mathrm{Ca}^{2+}\right]_{\text {ext }}$ aCSF to test whether conditions that would increase the release of endogenous ACh might alter the extent and/or time course of nAChR-mediated modulation. In this experimental setting, the same stimulus paradigm induced up to a 10-fold increase in the frequency of sIPSCs without significant alteration of sIPSC amplitude (average enhancement, $554 \pm 263 \%$ of control; baseline frequency, $2.9 \pm 1 \mathrm{~Hz}$; mean amplitude: control, $27 \pm 4 \mathrm{pA}$; after, $31 \pm 3 \mathrm{pA} ; p>0.05 ; n=5)($ Fig. $6 B, D)$. Likewise, in the presence of $5 \mathrm{~mm}$ external $\mathrm{Ca}^{2+}$, the delay between burst stimulation and elevated transmission was considerably decreased, although still substantial (from $\sim 13$ to $\sim 5$ min delay).

\section{Endogenous ACh-induced facilitation of GABAergic transmission involves activation of $\alpha 7^{\star}$ nicotinic receptor}

To further assess the participation of $\alpha 7^{\star}$ versus non- $\alpha 7^{\star}$ $n A C h R s$ in the modulation of GABAergic transmission, we assayed AChR-mediated synaptic facilitation in the presence of selective nAChR antagonists and in slices from mice that lack $\alpha 7$ nAChR expression $(\alpha 7-/-)$ (Orr-Urtreger et al., 1997). We first confirmed the involvement of nicotinic AChRs per se using broad-spectrum nAChR antagonists that do not discriminate nAChRs subtypes. Mecamylamine $(1 \mu \mathrm{M})$ completely blocked the facilitation of GABAergic transmission induced by either burst stimulation of cholinergic regions or increasing extracellular ACh by AChE inhibition $(n=8$; data not shown). To assess the possible contribution of $(\alpha \beta)^{\star} \mathrm{nAChRs}$, we tested for effects of dihydro- $\beta$-erythroidine (DH- $\beta$-E) (500 nM) on facilitated GABAergic transmission. Unlike mecamylamine, $\mathrm{DH}-\beta-\mathrm{E}$ was without effect on nAChR-mediated modulation $(n=6)$ (Fig. $7 A$ ). In contrast, the $\alpha 7$-selective antagonist $\alpha \operatorname{BgTx}(50 \mathrm{nM}$ ) completely blocked the facilitation of GABAergic transmission by increased $[\mathrm{ACh}]_{\text {ext }}$ attributable to treatment with AChE inhibitors $(n=6)$ (Fig. $7 A)$ or by extracellular stimulation of cholinergic neurons $(n=4)$ (Fig. $6 E$ ). In addition, a brief previous exposure of LH slice to low concentrations of nicotine is sufficient to block subsequent effects of AChEI, consistent with nAChR crossdesensitization (nicotine, $100 \mathrm{~nm}, 1 \mathrm{~min}$ ) (Fig. 7A). The crossdesensitization effect reversed within $15 \mathrm{~min}$ of washout (data not shown; $n=6$ ).

The involvement of $\alpha 7^{\star} \mathrm{nAChRs}$ in the modulation of GABAergic transmission was further supported by experiments in which we used genetically modified mice that lack $\alpha 7 \mathrm{nAChR}$ subunit gene expression ( $\alpha 7 \mathrm{KO}$ ). In 12 separate experiments on LH slices from $\alpha 7 \mathrm{KO}$ mice in which baseline GABAergic transmission was similar in amplitude and frequency to $+/+$ siblings, we never observed AChEI-induced synaptic facilitation (500 nM; $n=12$ ) (Fig. $7 A$ ).

In studies of triple immunostaining in WT slice with $\alpha \mathrm{BgTx}$ 
A

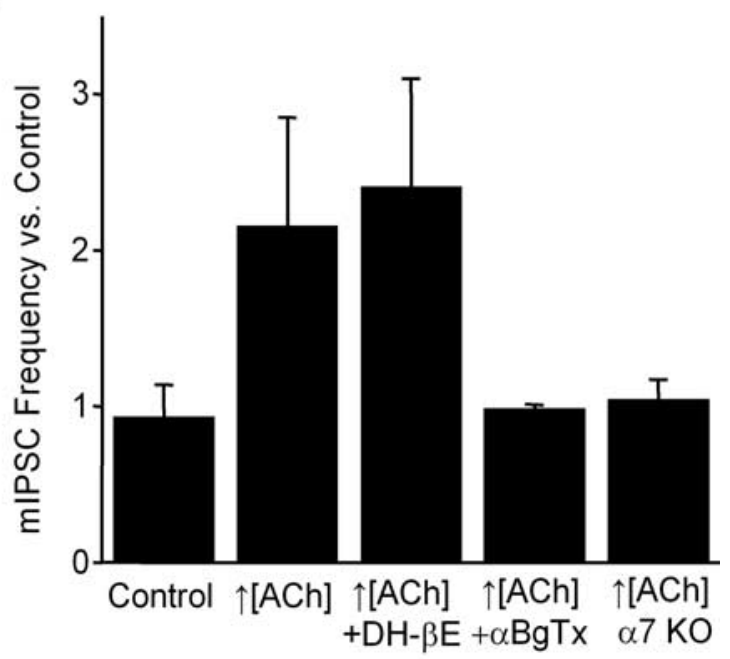

B

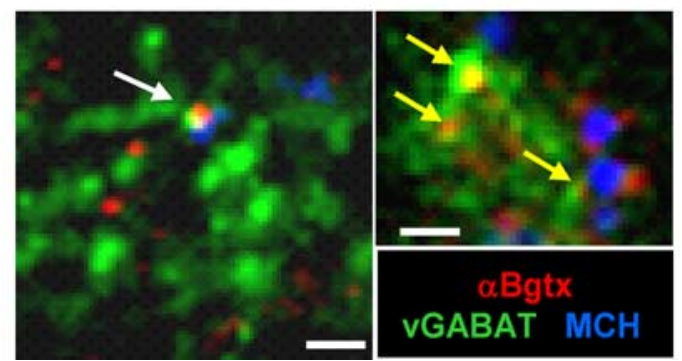

Figure 7. $n A C h R$-induced facilitation of GABAergic transmission involves activation of $\alpha 7$ containing nicotinic receptors. $\boldsymbol{A}$, Summary of experiments $(n=39)$ examining the pharmacology of nAChR-induced facilitation of GABAergic transmission. The $\alpha 7$-selective antagonist $\alpha B g T x(50 \mathrm{~nm})$, blocked the facilitation of GABAergic transmission elicited by nicotine ( $500 \mathrm{~nm}$ to $1 \mu \mathrm{m}$ ) or by inhibition of AChE (ambenomium; $500 \mathrm{~nm}$ ), whereas DH- $\beta$-E was without effect. Application of AChE inhibitors elicited no detectable change in GABA release in 12 separate experiments on $\mathrm{LH}$ slices from $\alpha 7 \mathrm{KO}$ mice. $\boldsymbol{B}$, Triple immunostaining was performed with primary antibodies directed against $\mathrm{MCH}$ (visualized with secondary antibody coupled to 7-amino-4-methylcoumarin-3-acetic acid; blue), the vesicular transporter for GABA (green), and with a directly conjugated $\alpha 7 \mathrm{nAChR}$-selective toxin, $\alpha \mathrm{BgTx}$ (red). Structures positive for vGABAT and $\alpha$ BgTx staining (yellow arrows) can be detected in close proximity to MCH-positive dendrites (white arrow). Scale bar, $6 \mu \mathrm{m}$

and antibodies for $\mathrm{MCH}$ and vesicular GABA transporter (vGABAT), we could detect sites in which both vGABATimmunopositive and $\alpha \mathrm{BgTx}$-positive structures appeared adjacent to MCH-positive dendrites (Fig. 7B). Together, these electrophysiological and immunocytochemical data implicate $\alpha 7^{\star}$ nAChRs in the ACh-induced facilitation of GABAergic transmission at synapses to the $\mathrm{LH} / \mathrm{MCH}$ neurons.

Exposure to nicotine during mid-prenatal and early perinatal period exerts long-lasting effects on inhibitory inputs to $\mathrm{LH}$ and attenuates nAChR-mediated facilitation of GABAergic transmission

In view of our findings implicating presynaptic $n A C h R$ activation in the modulation of GABAergic inputs to $\mathrm{LH} / \mathrm{MCH}$ neurons, we initiated tests of whether exposure to nicotine during prenatal and early perinatal development would influence the profile of inhibitory transmission in postnatal pups. In studies described above and in previous published work on GABAergic transmission in LH neurons in vitro, brief application of nicotine at concentrations of $0.5-1 \mu \mathrm{M}$ has been shown to elicit a brisk but transient increase in GABAergic transmission (Figs. 3E, 7A) (Jo and Role, 2002).

Pregnant WT mice were exposed to nicotine from postcoital day 14 through weaning and inhibitory transmission to PF LH neurons was monitored in offspring at P14-P21 to assess the effects of perinatal nicotine exposure. Perinatal nicotine exposure resulted in dramatic differences in baseline GABAergic transmission and abolished the effects of subsequent applications of acute nicotine in the modulation of GABAergic transmission (Fig. 8).

GABAergic transmission in hypothalamic slices of pups from WT control versus WT nicotine-exposed moms was examined by monitoring the frequency and amplitude of sIPSCs. The average baseline frequency of sIPSCs was increased approximately sevenfold in nicotine-exposed groups compared with the control group (control, $2 \pm 0.8 \mathrm{~Hz}, n=7$; nicotine-exposed, $13.9 \pm 3.5$ $\mathrm{Hz}, n=8$ ) (Fig. 8, compare $A$ with $B, D$ ). The mean amplitude of sIPSCs in perinatal nicotine-exposed pups was also increased compared with control (from $33.5 \pm 3.4 \mathrm{pA}, n=7$ cells to $72.1 \pm$ $20.3 \mathrm{pA}, n=8$ cells) (Fig. $8 D$ ).

Finally, we compared the effect of brief applications of nicotine on GABA release in prenatal nicotine-exposed versus control pups (Fig. 8, compare $A$ with $B, E$ ). Whereas application of nicotine $(500 \mathrm{nM}$ to $1 \mu \mathrm{M}$ ) increased GABAergic transmission in control pups, it was without effect in nicotine-exposed animals [Fig. $8 E$ (mean change in the frequency, $12 \pm 6 \% ; n=8$ ), $C, G$ (mean increase, $98 \pm 36 \% ; n=6$ )]. These electrophysiological findings complement recent behavioral studies on the effects of prenatal nicotine exposure and nAChR mutant mice (Cohen et al., 2005)

\section{Discussion}

There are three principle findings of this study. The first is that $\mathrm{MCH}$-expressing neurons appear to be distinguishable from other perifornical LH neurons by combined analysis of electrophysiology, morphology, immunostaining, and mRNA expression profile. The second major finding of this work is that released ACh modulates the synaptic excitability of the $\mathrm{LH} / \mathrm{MCH}$ neurons via activation of presynaptic nicotinic AChRs. Finally, initial studies indicate that perinatal exposure to nicotine enhances tonic GABAergic input to $\mathrm{LH}$ and attenuates nicotinic modulation of inhibitory transmission in postnatal pups.

Previous studies have demonstrated that activation of presynaptic nAChRs by exogenous application of nicotinic agonists can alter the release of neurotransmitters, including glutamate, GABA, glycine, and dopamine (for review, see Berg and Conroy, 2002; Alkondon and Albuquerque, 2004; Dajas-Bailador and Wonnacott, 2004; Mansvelder et al., 2005) (McMahon et al., 1994; McGehee et al., 1995; Alkondon et al., 1997; Zhu and Chiappinelli, 1999; Wonnacott et al., 2000; Kiyosawa et al., 2001; Mansvelder et al., 2002). In addition, direct nAChR-mediated, fast synaptic transmission occurs in several brain areas (Jones and Yakel, 1997; Alkondon et al., 1998; Frazier et al., 1998; Hefft et al., 1999; Nong et al., 1999). The broad distribution of nAChRexpressing neurons and the diffuse pattern of cholinergic projections throughout the brain contrast with the relatively low levels of total $\mathrm{nAChR}$ expression. These characteristics of the nicotinic cholinergic system in the CNS, along with the paucity of classical presynaptic profiles at sites of cholinergic projection, has led to the proposal that ACh released as a "volume transmitter" may be a primary mechanism for $\mathrm{nAChR}$ activation in the CNS (Descarries et al., 1997). In this view, tonic released ACh may play an important role in the fine-tuned modulation of synaptic transmission. 
Prenatal Control Group

A

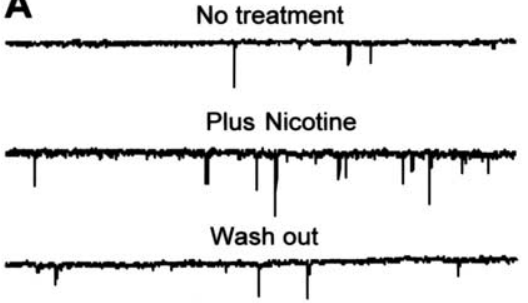

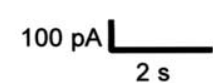

C

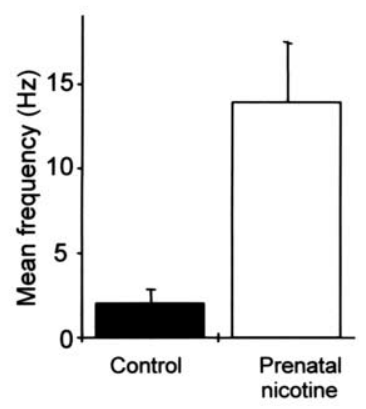

D

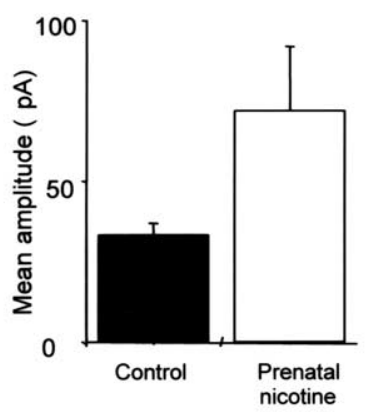

Nicotine -treated Group

B

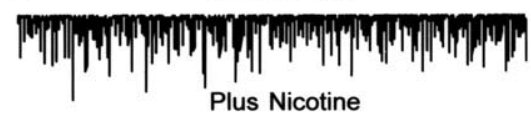

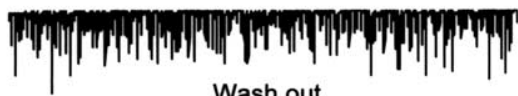

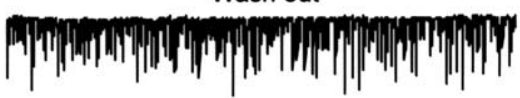

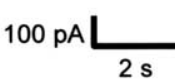

E

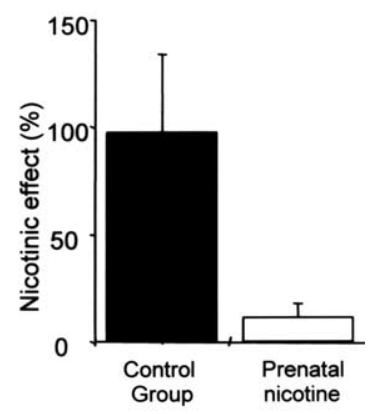

Figure 8. Perinatal exposure to nicotine causes long-lasting increases in tonic GABAergic transmission and ablates short-term $\mathrm{nAChR}$ modulation in LH. The effects of perinatal exposure (from postcoital day 14 to weaning) to nicotine were evaluated by recording in slices from 2- to 4-week-old pups. $A$, Representative recordings from PF LH neurons in acute slice from control group ( $n=7$ ) showing baseline spontaneous GABAergic transmission (top trace), increased sIPSC frequency elicited by brief application of nicotine (Plus Nicotine; $3 \mathrm{~min}, 500 \mathrm{~nm}$ ), and the return to baseline activity $15 \mathrm{~min}$ after washout of nicotine (bottom trace). $\boldsymbol{B}$, Representative recordings from PF LH neuron in acute slice from perinatal nicotine-treated group $(n=8)$ showing baseline spontaneous GABAergic transmission before (top trace), during (middle trace), and 15 min after application of nicotine (Plus Nicotine). Prenatal exposure to nicotine elevates GABAergic transmission and blocks nicotine-induced facilitation. $\boldsymbol{C}-\boldsymbol{E}$, Summary of the effects of perinatal exposure to nicotine on the baseline frequency $(\boldsymbol{C})$ and amplitude $(\boldsymbol{D})$ of GABAergic sIPSCs. $\boldsymbol{E}$ summarizes the effects of acute nicotine application in slices from pups exposed to nicotine versus those maintained under control conditions in the prenatal and perinatal periods as delineated in Materials and Methods.

\section{ACh-induced facilitation of GABAergic transmission via $\alpha 7^{\star}$ nAChRs}

A few previous studies have provided evidence for significant effects of endogenously released ACh in the modulation of CNS synapses via nicotinic AChRs (Maggi et al., 2001; Zhou et al., 2001; Mansvelder et al., 2002). In a previous study (Jo and Role, 2002), we studied the effects of direct ACh receptor activation in the lateral hypothalamic synapses in vitro. Treatment with nicotine strongly facilitated GABAergic transmission at LH synapses, whereas the activation of muscarinic AChRs depressed GABAergic transmission.

The current study examines the role of endogenous cholinergic systems in nAChR modulation of LH neurons in more intact brain slice preparations. Inhibition of AChE results in an elevation of ACh that, like the application of nicotine, elicits a significant enhancement of GABAergic transmission to LH/ $\mathrm{MCH}$ neurons. Inhibition of AChE may mimic physiological conditions in which tonic levels of released ACh can facilitate GABAergic transmission. Pharmacological and immunocytochemical studies, as well as tests in genetically modified mice that lack $\alpha 7 \mathrm{nAChR}$ subunit gene expression indicate that endogenous ACh-induced facilitation of GABAergic transmission involves activation of $\alpha 7^{\star}$ nicotinic receptors.

High-frequency burst stimulation of regions within and around the LH that include cholinergic cell groups also triggered an nAChR-dependent ( $\alpha$ BgTx blockable) facilitation of GABAergic transmission in PF LH. A simple interpretation of the stimulus-evoked, nAChR-mediated facilitation of GABAergic transmission would be that activation of local cholinergic neurons results in increased ACh release, which then activates presynaptic nAChRs on GABAergic projections (Mulle et al., 1992; McMahon et al., 1994; Mansvelder et al., 2002). Stimulus-evoked facilitation was reproducibly blocked by either mecamylamine or $\alpha \mathrm{BgTx}$, indicating that the modulation required $\mathrm{nAChR}$ activation. More complex scenarios, however, are indicated by the observation of extensive delays (10 $\mathrm{min}$ ) between the stimulus burst and nAChR-dependent facilitation of transmission. The prolonged delay was unaffected by poststimulus exposure to TTX, suggesting that the mechanism(s) underlying the delay are action potential independent (data not shown). Blockers of muscarinic AChRs and of both AMPAand NMDA-type receptors did not effect the delay. In contrast, increasing external $\mathrm{Ca}$ (from 2.5 to $5 \mathrm{~mm}$ ) or perfusion temperature (from $\sim 26$ to $\sim 32^{\circ} \mathrm{C}$ ) or lowering perfusion rate decreased the delay, although several minutes still elapsed between stimulation and increased GABAergic transmission. The mechanism of the delay remains a puzzle.

Prolonged delays from stimulus to release of transmitter have been noted in growing neurons and at newly developed synapses (Hume et al., 1983; Young and Poo, 1983; Poo et al., 1985). Long delays after tetanic stimulation is also reminiscent of "silent synapses," a phenomenon attributed to both presynaptic and postsynaptic plasticity (Liao et al., 1995; Malenka and Nicoll, 1997; Gasparini et al., 2000). Our slices were routinely from P14-P17 mice, and the cholinergic projections, although present, may be immature. The burst stimulus used may be of limited efficacy because of immature and/or low probability of release or rapid synaptic fatigue (Zengel and Magleby, 1981; Grinnell et al., 1989). Alternatively, if relatively high levels of ACh release are required for action as a volume transmitter, diffusion and local AChE activity may be rate limiting. A recent study demonstrates that presynaptic $\alpha 7 \mathrm{nAChRs}$ are often located at extrasynaptic loci in the rat ventral tegmental area and that $\alpha 7 \mathrm{nAChRs}$ are not directly apposed to cholinergic fibers consistent with their activation by a paracrine mode of acetylcholine release (Jones and Wonnacott, 2004).

\section{Prenatal exposure to nicotine}

In vivo exposure to drugs of abuse has been shown to elicit changes in synaptic strength within neuronal circuits associated with reward (Ungless et al., 2001; Melis et al., 2002; Saal et al., 2003). Administration of drugs of abuse, such as cocaine, nicotine, and morphine induces a long-term change of glutamatergic synaptic transmission in midbrain dopamine neurons (Ungless et al., 2001; Saal et al., 2003). In vivo ethanol exposure also in- 
duces long-lasting potentiation of GABAergic synapses in dopamine neurons (Melis et al., 2002). These previous reports indicate that a single exposure to drugs of abuse could induce long-term changes in synaptic activity.

Despite numerous studies of regulation of the expression and/or function of $\mathrm{nAChRs}$ by chronic nicotine exposure in vivo and in vitro (Yates et al., 1995; Olale et al., 1997; Peng et al., 1997; Ke et al., 1998; Molinari et al., 1998; Wang et al., 1998; Fenster et al., 1999; Buisson and Bertrand, 2001; Gentry and Lukas, 2002; Slotkin et al., 2002; Pakkanen et al., 2005), little information is available about the effect of prenatal nicotine exposure on synaptic activity in the CNS in general and in the hypothalamus in particular. Hence, we sought to define whether prenatal exposure to nicotine alters the inhibitory input to LH or alters cholinergic modulation in the postnatal animal. Our initial studies suggest that offspring of nicotine-exposed pregnant mice may have persistent increases in inhibitory tone in lateral hypothalamic circuits.

Based on current findings and on previous results, we propose that the anorexigenic effects of nicotine exposure may be associated with a decrease in the excitability of $\mathrm{LH} / \mathrm{MCH}$ neurons via increases in GABAergic inhibitory tone. Consistent with this idea, continuous exposure to nicotine in the prenatal animal enhanced the baseline activity of GABAergic transmission to LH/ $\mathrm{MCH}$ neurons. Such increased inhibitory tone in the LH could decrease the net excitability of LH neurons associated with motivational aspects of feeding. This is consistent with previous studies showing that in vivo exposure to drugs of abuse, including cocaine, nicotine, morphine, and ethanol, enhances glutamatergic as well as GABAergic transmission in reward neural circuit (Ungless et al., 2001; Melis et al., 2002; Saal et al., 2003). The mechanism underlying this upregulation of inhibitory tone remains to be explained. One simple explanation is that the loss of presynaptic nAChRs in nicotine-exposed mice may alter GABA release at LH synapses (Cohen et al., 2005).

Activation of presynaptic nAChRs by ambient ACh strongly enhances GABA release in control preparations. If prenatal nicotine exposure downregulates the expression of presynaptic $\alpha 7^{\star}$ $n A C h R s$, then such increased inhibitory tone may reflect compensatory upregulation in the release of GABA per se. Additional mechanisms may also contribute to the increased GABAergic transmission. For example, perinatal exposure to nicotine may upregulate the number of $\mathrm{GABA}_{\mathrm{A}}$ receptors on postsynaptic neurons, unmask silent GABAergic synapses, and/or increase the number of GABAergic release sites.

Numerous studies demonstrate that chronic nicotine exposure results in an upregulation of nAChRs in several preparations (Yates et al., 1995; Olale et al., 1997; Peng et al., 1997; Ke et al., 1998; Molinari et al., 1998; Wang et al., 1998; Fenster et al., 1999; Buisson and Bertrand, 2001; Slotkin et al., 2002). In contrast, we find that pups subject to prenatal nicotine exposure were unresponsive to the effects of postnatal nAChR activation. Together, it appears that prenatal exposure to nicotine can alter the synaptic strength and plasticity of GABAergic inputs to PF LH neurons by increasing inhibitory tone and by attenuating cholinergic modulation of LH synapses.

\section{Potential physiological significance}

These studies initiate tests of the hypothesis that appetite-related circuits within the hypothalamus are subject to modulation via the activation of presynaptic nicotinic AChRs. Despite the well known appetite-suppressant effect of nicotine self-administration and the appetite-stimulating effects of nicotine cessation, the mechanisms underlying nicotine effects on feeding remain elusive. We propose that the effects of nicotine administration and its withdrawal may result, at least in part, from $\mathrm{nAChR}$-mediated changes in the balance of synaptic excitability of the $\mathrm{LH} / \mathrm{MCH}$ neurons for several reasons. First, nicotine administration into the LH significantly decreases food intake (Miyata et al., 1999; Yang et al., 1999; Miyata et al., 2001). Second, nicotine alters the expression of feeding-related neuropeptides and their receptors within the LH (Frankish et al., 1995; Kane et al., 2000; Li et al., 2000a,b; Kane et al., 2001). Third, nicotine treatment elicits both short- and long-term changes in the release of a variety of transmitters in LH (Miyata et al., 1999; Meguid et al., 2000; Li and Pan, 2001; Zhang et al., 2001). Current studies reveal that either direct application of nicotine or increased levels of ACh in the LH facilitates GABAergic transmission. Finally, there is robust enhancement of GABAergic transmission after in vivo, prenatal exposure to nicotine. Activation of presynaptic nAChRs on GABAergic interneurons may offset the pro-appetite, orexigenic signaling of endocannabinoids (Jo et al., 2005), favoring a net inhibition of $\mathrm{MCH}$ positive neurons. Such synaptic tuning of LH neurons would explain, at least in part, the anorexigenic activity of nicotine.

\section{References}

Alkondon M, Albuquerque EX (2004) The nicotinic acetylcholine receptor subtypes and their function in the hippocampus and cerebral cortex. Prog Brain Res 145:109-120.

Alkondon M, Pereira EF, Barbosa CT, Albuquerque EX (1997) Neuronal nicotinic acetylcholine receptor activation modulates gammaaminobutyric acid release from CA1 neurons of rat hippocampal slices. J Pharmacol Exp Ther 283:1396-1411.

Alkondon M, Pereira EF, Albuquerque EX (1998) alpha-bungarotoxin- and methyllycaconitine-sensitive nicotinic receptors mediate fast synaptic transmission in interneurons of rat hippocampal slices. Brain Res 810:257-263.

Bayer L, Risold PY, Griffond B, Fellmann D (1999) Rat diencephalic neurons producing melanin-concentrating hormone are influenced by ascending cholinergic projections. Neuroscience 91:1087-1101.

Berg DK, Conroy WG (2002) Nicotinic alpha 7 receptors: synaptic options and downstream signaling in neurons. J Neurobiol 53:512-523.

Buisson B, Bertrand D (2001) Chronic exposure to nicotine upregulates the human $\alpha 4 \beta 2$ nicotinic acetylcholine receptor function. J Neurosci 21:1819-1829.

Cohen G, Roux JC, Grailhe R, Malcolm G, Changeux JP, Lagercrantz H (2005) Perinatal exposure to nicotine causes deficits associated with a loss of nicotinic receptor function. Proc Natl Acad Sci USA 102:3817-3821.

Dajas-Bailador F, Wonnacott S (2004) Nicotinic acetylcholine receptors and the regulation of neuronal signalling. Trends Pharmacol Sci 25:317-324.

Descarries L, Gisiger V, Steriade M (1997) Diffuse transmission by acetylcholine in the CNS. Prog Neurobiol 53:603-625.

Eggermann E, Bayer L, Serafin M, Saint-Mleux B, Bernheim L, Machard D, Jones BE, Muhlethaler M (2003) The wake-promoting hypocretinorexin neurons are in an intrinsic state of membrane depolarization. J Neurosci 23:1557-1562.

Fenster CP, Whitworth TL, Sheffield EB, Quick MW, Lester RA (1999) Upregulation of surface $\alpha 4 \beta 2$ nicotinic receptors is initiated by receptor desensitization after chronic exposure to nicotine. J Neurosci 19:4804-4814.

Frankish HM, Dryden S, Wang Q, Bing C, MacFarlane IA, Williams G (1995) Nicotine administration reduces neuropeptide $\mathrm{Y}$ and neuropeptide $\mathrm{Y}$ mRNA concentrations in the rat hypothalamus: NPY may mediate nicotine's effects on energy balance. Brain Res 694:139-146.

Frazier CJ, Buhler AV, Weiner JL, Dunwiddie TV (1998) Synaptic potentials mediated via $\alpha$-bungarotoxin-sensitive nicotinic acetylcholine receptors in rat hippocampal interneurons. J Neurosci 18:8228-8235.

Gao XB, Ghosh PK, Van Den Pol AN (2003) Neurons synthesizing melaninconcentrating hormone identified by selective reporter gene expression after transfection in vitro: transmitter responses. J Neurophysiol 90:3978-3985.

Gasparini S, Saviane C, Voronin LL, Cherubini E (2000) Silent synapses in the developing hippocampus: lack of functional AMPA receptors or low probability of glutamate release? Proc Natl Acad Sci USA 97:9741-9746. 
Gentry CL, Lukas RJ (2002) Regulation of nicotinic acetylcholine receptor numbers and function by chronic nicotine exposure. Curr Drug Target CNS Neurol Disord 1:359-385.

Grinnell AD, Gundersen CB, Meriney SD, Young SH (1989) Direct measurement of ACh release from exposed frog nerve terminals: constraints on interpretation of non-quantal release. J Physiol (Lond) 419:225-251.

Grove EA (1988) Efferent connections of the substantia innominata in the rat. J Comp Neurol 277:347-364.

Grunberg NE (1986) Nicotine as a psychoactive drug: appetite regulation. Psychopharmacol Bull 22:875-881.

Grunberg NE, Bowen DJ, Winders SE (1986) Effects of nicotine on body weight and food consumption in female rats. Psychopharmacology (Berl) 90:101-105.

Hefft S, Hulo S, Bertrand D, Muller D (1999) Synaptic transmission at nicotinic acetylcholine receptors in rat hippocampal organotypic cultures and slices. J Physiol (Lond) 515:769-776.

Hodge AS, Humphrey DR, Rosenberry TL (1992) Ambenonium is a rapidly reversible noncovalent inhibitor of acetylcholinesterase, with one of the highest known affinities. Mol Pharmacol 41:937-942.

Hume RI, Role LW, Fischbach GD (1983) Acetylcholine release from growth cones detected with patches of acetylcholine receptor-rich membranes. Nature 305:632-634.

Jo Y, Chen Y, Chua S, Talmage D, Role L (2005) Integration of endocannabinoid and leptin signaling in an appetite-related neural circuit. Neuron, in press.

Jo YH, Role LW (2002) Cholinergic modulation of purinergic and GABAergic co-transmission at in vitro hypothalamic synapses. J Neurophysiol 88:2501-2508.

Jo YH, Talmage DA, Role LW (2002) Nicotinic receptor-mediated effects on appetite and food intake. J Neurobiol 53:618-632.

Jones IW, Wonnacott S (2004) Precise localization of $\alpha 7$ nicotinic acetylcholine receptors on glutamatergic axon terminals in the rat ventral tegmental area. J Neurosci 24:11244-11252.

Jones S, Yakel JL (1997) Functional nicotinic ACh receptors on interneurones in the rat hippocampus. J Physiol (Lond) 504:603-610.

Kane JK, Parker SL, Matta SG, Fu Y, Sharp BM, Li MD (2000) Nicotine up-regulates expression of orexin and its receptors in rat brain. Endocrinology 141:3623-3629.

Kane JK, Parker SL, Li MD (2001) Hypothalamic orexin-A binding sites are downregulated by chronic nicotine treatment in the rat. Neurosci Lett 298:1-4.

Ke L, Eisenhour CM, Bencherif M, Lukas RJ (1998) Effects of chronic nicotine treatment on expression of diverse nicotinic acetylcholine receptor subtypes. I. Dose- and time-dependent effects of nicotine treatment. J Pharmacol Exp Ther 286:825-840.

Kiyosawa A, Katsurabayashi S, Akaike N, Pang ZP (2001) Nicotine facilitates glycine release in the rat spinal dorsal horn. J Physiol (Lond) 536:101-110.

Klesges RC, Meyers AW, Klesges LM, La Vasque ME (1989) Smoking, body weight, and their effects on smoking behavior: a comprehensive review of the literature. Psychol Bull 106:204-230.

Li DP, Pan HL (2001) Potentiation of glutamatergic synaptic input to supraoptic neurons by presynaptic nicotinic receptors. Am J Physiol Regul Integr Comp Physiol 281:R1105-R1113.

Li MD, Parker SL, Kane JK (2000a) Regulation of feeding-associated peptides and receptors by nicotine. Mol Neurobiol 22:143-165.

Li MD, Kane JK, Parker SL, McAllen K, Matta SG, Sharp BM (2000b) Nicotine administration enhances NPY expression in the rat hypothalamus. Brain Res 867:157-164.

Li Y, Gao XB, Sakurai T, van den Pol AN (2002) Hypocretin/orexin excites hypocretin neurons via a local glutamate neuron-A potential mechanism for orchestrating the hypothalamic arousal system. Neuron 36:1169-1181.

Liao D, Hessler NA, Malinow R (1995) Activation of postsynaptically silent synapses during pairing-induced LTP in CA1 region of hippocampal slice. Nature 375:400-404.

Liu XH, Morris R, Spiller D, White M, Williams G (2001) Orexin a preferentially excites glucose-sensitive neurons in the lateral hypothalamus of the rat in vitro. Diabetes 50:2431-2437.

Maggi L, Sher E, Cherubini E (2001) Regulation of GABA release by nicotinic acetylcholine receptors in the neonatal rat hippocampus. J Physiol (Lond) 536:89-100.
Malenka RC, Nicoll RA (1997) Silent synapses speak up. Neuron 19:473-476.

Mansvelder HD, Keath JR, McGehee DS (2002) Synaptic mechanisms underlie nicotine-induced excitability of brain reward areas. Neuron 33:905-919.

Mansvelder HD, van Aerde KI, Couey JJ, Brussaard AB (2005) Nicotinic modulation of neuronal networks: from receptors to cognition. Psychopharmacology (Berl), in press.

Marsh DJ, Weingarth DT, Novi DE, Chen HY, Trumbauer ME, Chen AS, Guan XM, Jiang MM, Feng Y, Camacho RE, Shen Z, Frazier EG, Yu H, Metzger JM, Kuca SJ, Shearman LP, Gopal-Truter S, MacNeil DJ, Strack AM, MacIntyre DE, et al. (2002) Melanin-concentrating hormone 1 receptor-deficient mice are lean, hyperactive, and hyperphagic and have altered metabolism. Proc Natl Acad Sci USA 99:3240-3245.

McGehee DS, Heath MJ, Gelber S, Devay P, Role LW (1995) Nicotine enhancement of fast excitatory synaptic transmission in CNS by presynaptic receptors. Science 269:1692-1696.

McMahon LL, Yoon KW, Chiappinelli VA (1994) Nicotinic receptor activation facilitates GABAergic neurotransmission in the avian lateral spiriform nucleus. Neuroscience 59:689-698.

Meguid MM, Fetissov SO, Varma M, Sato T, Zhang L, Laviano A, RossiFanelli F (2000) Hypothalamic dopamine and serotonin in the regulation of food intake. Nutrition 16:843-857.

Melis M, Camarini R, Ungless MA, Bonci A (2002) Long-lasting potentiation of GABAergic synapses in dopamine neurons after a single in vivo ethanol exposure. J Neurosci 22:2074-2082.

Miyata G, Meguid MM, Fetissov SO, Torelli GF, Kim HJ (1999) Nicotine's effect on hypothalamic neurotransmitters and appetite regulation. Surgery 126:255-263.

Miyata G, Meguid MM, Varma M, Fetissov SO, Kim HJ (2001) Nicotine alters the usual reciprocity between meal size and meal number in female rat. Physiol Behav 74:169-176.

Molinari EJ, Delbono O, Messi ML, Renganathan M, Arneric SP, Sullivan JP, Gopalakrishnan M (1998) Up-regulation of human alpha7 nicotinic receptors by chronic treatment with activator and antagonist ligands. Eur J Pharmacol 347:131-139.

Mulle C, Choquet D, Korn H, Changeux JP (1992) Calcium influx through nicotinic receptor in rat central neurons: its relevance to cellular regulation. Neuron 8:135-143.

Nong Y, Sorenson EM, Chiappinelli VA (1999) Fast excitatory nicotinic transmission in the chick lateral spiriform nucleus. J Neurosci 19:7804-7811.

Oh JD, Woolf NJ, Roghani A, Edwards RH, Butcher LL (1992) Cholinergic neurons in the rat central nervous system demonstrated by in situ hybridization of choline acetyltransferase mRNA. Neuroscience 47:807-822.

Olale F, Gerzanich V, Kuryatov A, Wang F, Lindstrom J (1997) Chronic nicotine exposure differentially affects the function of human alpha3, alpha4, and alpha7 neuronal nicotinic receptor subtypes. J Pharmacol Exp Ther 283:675-683.

Orr-Urtreger A, Goldner FM, Saeki M, Lorenzo I, Goldberg L, De Biasi M, Dani JA, Patrick JW, Beaudet AL (1997) Mice deficient in the $\alpha 7$ neuronal nicotinic acetylcholine receptor lack $\alpha$-bungarotoxin binding sites and hippocampal fast nicotinic currents. J Neurosci 17:9165-9171.

Pakkanen JS, Jokitalo E, Tuominen RK (2005) Up-regulation of beta2 and alpha7 subunit containing nicotinic acetylcholine receptors in mouse striatum at cellular level. Eur J Neurosci 21:2681-2691.

Pauly JR, Sparks JA, Hauser KF, Pauly TH (2004) In utero nicotine exposure causes persistent, gender-dependant changes in locomotor activity and sensitivity to nicotine in C57Bl/6 mice. Int J Dev Neurosci 22:329-337.

Peng X, Gerzanich V, Anand R, Wang F, Lindstrom J (1997) Chronic nicotine treatment up-regulates alpha3 and alpha7 acetylcholine receptor subtypes expressed by the human neuroblastoma cell line SH-SY5Y. Mol Pharmacol 51:776-784.

Pomerleau CS, Pomerleau OF, Namenek RJ, Mehringer AM (2000) Shortterm weight gain in abstaining women smokers. J Subst Abuse Treat 18:339-342.

Poo MM, Sun YA, Young SH (1985) Three types of transmitter release from embryonic neurons. J Physiol (Paris) 80:283-289.

Rao ZR, Yamano M, Wanaka A, Tatehata T, Shiosaka S, Tohyama M (1987) Distribution of cholinergic neurons and fibers in the hypothalamus of the rat using choline acetyltransferase as a marker. Neuroscience 20:923-934. Saal D, Dong Y, Bonci A, Malenka RC (2003) Drugs of abuse and stress 
trigger a common synaptic adaptation in dopamine neurons. Neuron 37:577-582.

Shimada M, Tritos NA, Lowell BB, Flier JS, Maratos-Flier E (1998) Mice lacking melanin-concentrating hormone are hypophagic and lean. Nature 396:670-674.

Slotkin TA, Pinkerton KE, Auman JT, Qiao D, Seidler FJ (2002) Perinatal exposure to environmental tobacco smoke upregulates nicotinic cholinergic receptors in monkey brain. Brain Res Dev Brain Res 133:175-179.

Song Z, Levin BE, McArdle JJ, Bakhos N, Routh VH (2001) Convergence of pre- and postsynaptic influences on glucosensing neurons in the ventromedial hypothalamic nucleus. Diabetes 50:2673-2681.

Tago H, McGeer PL, Bruce G, Hersh LB (1987) Distribution of choline acetyltransferase-containing neurons of the hypothalamus. Brain Res 415:49-62.

Ungless MA, Whistler JL, Malenka RC, Bonci A (2001) Single cocaine exposure in vivo induces long-term potentiation in dopamine neurons. Nature 411:583-587.

van den Pol AN, Acuna-Goycolea C, Clark KR, Ghosh PK (2004) Physiological properties of hypothalamic $\mathrm{MCH}$ neurons identified with selective expression of reporter gene after recombinant virus infection. Neuron 42:635-652.

Wang F, Nelson ME, Kuryatov A, Olale F, Cooper J, Keyser K, Lindstrom J (1998) Chronic nicotine treatment up-regulates human alpha3 beta2 but not alpha 3 beta 4 acetylcholine receptors stably transfected in human embryonic kidney cells. J Biol Chem 273:28721-28732.

Wang R, Liu X, Hentges ST, Dunn-Meynell AA, Levin BE, Wang W, Routh VH (2004) The regulation of glucose-excited neurons in the hypothalamic arcuate nucleus by glucose and feeding-relevant peptides. Diabetes 53:1959-1965.
Wonnacott S, Kaiser S, Mogg A, Soliakov L, Jones IW (2000) Presynaptic nicotinic receptors modulating dopamine release in the rat striatum. Eur J Pharmacol 393:51-58.

Woolf NJ (1991) Cholinergic systems in mammalian brain and spinal cord. Prog Neurobiol 37:475-524.

Yang ZJ, Blaha V, Meguid MM, Oler A, Miyata G (1999) Infusion of nicotine into the LHA enhances dopamine and 5-HT release and suppresses food intake. Pharmacol Biochem Behav 64:155-159.

Yates SL, Bencherif M, Fluhler EN, Lippiello PM (1995) Up-regulation of nicotinic acetylcholine receptors following chronic exposure of rats to mainstream cigarette smoke or alpha 4 beta 2 receptors to nicotine. Biochem Pharmacol 50:2001-2008.

Young SH, Poo MM (1983) Spontaneous release of transmitter from growth cones of embryonic neurones. Nature 305:634-637.

Zengel JE, Magleby KL (1981) Changes in miniature endplate potential frequency during repetitive nerve stimulation in the presence of $\mathrm{Ca}^{2+}$, $\mathrm{Ba}^{2+}$, and $\mathrm{Sr}^{2+}$ at the frog neuromuscular junction. J Gen Physiol 77:503-529.

Zhang L, Meguid MM, Miyata G, Varma M, Fetissov SO (2001) Role of hypothalamic monoamines in nicotine-induced anorexia in menopausal rats. Surgery 130:133-142.

Zhou FM, Liang Y, Dani JA (2001) Endogenous nicotinic cholinergic activity regulates dopamine release in the striatum. Nat Neurosci 4:1224-1229.

Zhu PJ, Chiappinelli VA (1999) Nicotine modulates evoked GABAergic transmission in the brain. J Neurophysiol 82:3041-3045.

Zwart R, Van Kleef RG, Vijverberg HP (1999) Physostigmine and atropine potentiate and inhibit neuronal alpha 4 beta 4 nicotinic receptors. Ann NY Acad Sci 868:636-639. 